\begin{tabular}{|c|c|c|c|c|c|}
\hline MUNIBE Antropologia-Arkeologia & $n^{\circ} 70$ & $109-134$ & DONOSTIA & 2019 & ISSN 1132-2217 • eISSN 2172-4555 \\
\hline
\end{tabular}

\title{
SIG y análisis espacial de la distribución territorial y funcional del Neolítico en la sierra de Atapuerca (Burgos) y la cuenca del Arlanzón (VI-IV milenio cal BC)
}

\author{
GIS spatial analysis of the Neolithic territorial and functional distribution
} at Sierra de Atapuerca (Burgos) and the Arlanzón Basin (VI-IV millennium cal BC)

\author{
PALABRAS CLAVES: Arqueología del Paisaje. Arqueología Espacial. SIG. Análisis Territorial. Estadística Espacial. \\ GAKO-HITZAK: Paisaiaren arkeologia. Espazioaren arkeologia. GIS. Lurraldearen azterketa. Espazioaren estatistika. \\ KEY WORDS: Landscape Archaeology. Spatial Archaeology. GIS. Territorial Analysis. Spatial Statistics.
}

Francisco Javier MARCOS SAIZ(1)

\section{RESUMEN}

Este trabajo presenta con las técnicas geoespaciales y estadísticas del SIG un análisis territorial del Neolítico de la sierra de Atapuerca y la cuenca del Arlanzón (Burgos) (VI-IV milenio cal BC). El trabajo de campo está basado en excavaciones (cuevas, túmulos y sitios de exterior) y en 10 prospecciones sistemáticas intensivas de cobertura total sobre un área de $314 \mathrm{~km}^{2}$ (10 km de radio de Cueva Mayor). El mapeo de los sitios con Modelos Digitales del Terreno (MDTs), la clasificación funcional con datos tecnoculturales y las técnicas de análisis espacial del SIG han sido las herramientas más útiles para proporcionar nueva información del poblamiento. El Neolítico del territorio (VI-IV milenio cal BC) manifiesta una densa articulación funcional de sitios con una estrategia de subsistencia agropecuaria: cuevas y galerías (zonas habitacionales y de estabulación del ganado, zonas funerarias y espacios simbólicos), estructuras funerarias megalíticas, poblados, campamentos, talleres de sílex y otros sitios con actividades económicas complementarias.

\section{LABURPENA}

Lan honek GISeko teknika geoespazialekin eta estatistikoekin egindako Neolitoko lurralde mailako azterketa jasotzen du. Azterketa Atapuerca mendizerran eta Arlanzoneko arroan (Burgos) egin da (K.a. VI-IV. milurtekoa, gutxi gorabehera). Landa-lana 314 km²-ko (Cueva Mayorreko $10 \mathrm{~km}$-ko erradioa) area batean egindako guztizko estaldurako 10 prospekzio sistematiko intentsibotan eta egindako indusketetan (kobazuloak, tumuluak eta kanpoko tokiak) oinarrituta dago. Herrixka haren inguruko informazio berria lortzeko tresna erabilgarrienak honako hauek izan dira: Lurra Eredu Digitalekin (MDT) tokien mapaketa, sailkapen funtzionala egitea datu teknokulturalekin eta GISeko azterketa espazialeko teknikak. Lurraldeko Neolitoak (K.a. VI-IV. milurtekoa, gutxi gorabehera) agerian uzten du bizibidea nekazaritza eta abeltzaintzatik ateratzen zuten tokien artikulazio funtzionala trinkoa zela: kobazuloak eta meazuloak (bizitzeko eta ganadua ukuiluratzeko eremuak, hileta eremuak eta gune sinbolikoak), hileta-egitura megalitikoak, herrixkak, kanpamentuak, silexa lantzeko tailerrak eta jarduera ekonomiko osagarriko beste toki batzuk).

\section{ABSTRACT}

This paper presents with the GIS geospatial and statistical techniques a territorial analysis of the Neolithic sites from Sierra de Atapuerca and the Arlanzón Basin (Burgos) (VI-IV millennium cal BC). The area around Sierra de Atapuerca is a geostrategic territory for knowledge of the neolithisation process on the Northern Iberian Plateau. The Early Neolithic radiocarbon datings on short-life samples from Mayor Cave and El Mirador Cave (Sierra de Atapuerca) are amongst the oldest of this period on the North Plateau (last third of the VI millennium cal BC; ca. 5400/5300 cal $\mathrm{BC}$ ). Sierra de Atapuerca is the final Cretaceous spur in the north-western part of the Iberian Range, it is close to the Basque-Cantabrian Mesozoic boundary, the nearby Bureba Depression is a natural corridor, there is a diversity of Paleozoic, Mesozoic and Cenozoic material around Sierra de la Demanda (Iberian Range), and the boundary between the Duero and Ebro River basins all formed a highly propitious geological, geomorphological, edaphic and palaeoecological context for Neolithic settlements. The Neogene and Cretaceous flint outcrops in the study area, of considerable quality for prehistoric technology, are another aspect of geological and palaeoeconomic importance.

The fieldwork was based on several systematic excavations (caves, megalithic mounds and open-air sites) and on ten full-coverage intensive systematic surveys in a $314 \mathrm{~km}^{2}$ study area (10 km radius around Mayor Cave). The results of the full-coverage intensive systematic survey project have proven highly successful, with near of 200 archaeological sites from the Neolithic, Chalcolithic and the Bronze Age in the $314 \mathrm{~km}^{2}$ study area. The mapping of all Neolithic sites with Digital Terrain Models (DTMs) of high resolution (10 m cell size), the site functional classification with techno-cultural data (the Multivariate Analysis of techno-typological variables of the lithic and ceramic tools) and the GIS spatial analysis techniques have been the most useful tools to provide new insights about the Neolithic settlement. The neolithisation process of this territory is one of the oldest on the Northern Iberian Plateau, which refutes the old historiographic claims of settlement gaps and delayed

\footnotetext{
(1) Laboratorio de Prehistoria. Departamento de Historia, Geografía y Comunicación. Universidad de Burgos. Edificio I+D+i. Plaza Misae Bañuelos s/n. 09001. Burgos. Correo e.: f.javiermarcos@hotmail.com
} 
areas. Domestic agrotypes of wheat and barley, ovicaprid livestock, Neolithic pottery, shaped and polished tools are all present in the karst records and the open air sites from the VI millennium cal BC. The Neolithic of this territory shows a dense functional articulation of sites from the VI to the IV millennium cal BC with a subsistence agriculture and livestock strategy: caves and galleries (inhabitation zones and livestock stabling, funerary zones and symbolic spaces), megalithic funerary structures, settlements, campsites, flintknapping workshops and other sites with complementary economic activities.

\section{INTRODUCCIÓN}

La escasez de proyectos de Arqueología del Paisaje sobre el Neolítico de la Meseta Norte (VI-IV milenio cal BC) es manifiesta en la historiografía. Los restos arqueoestratigráficos y las dataciones radiocarbónicas sobre muestras de vida corta de las cuevas de la sierra de Atapuerca (Burgos) (Carretero et al., 2008; Ortega et al., 2008; Alday et al., 2015; Vergés et al., 2016), de los poblados del valle de Ambrona (Soria) (Rojo et al., 2008) y de la Cueva de La Vaquera (Segovia) (Estremera, 2003) han sido esenciales para refutar viejas hipótesis sobre el Neolítico meseteño. Por ejemplo, la neolitización del sector oriental de la Meseta Norte no es un proceso retardatario y marginal, sino que la economía agropecuaria comienza en estos territorios hacia el 5400/5300 cal BC con cuevas y poblados al aire libre.

Sin embargo, muy poco sabemos de las estrategias territoriales de estas comunidades agropecuarias. Es necesario, por tanto, emprender nuevos estudios sobre el poblamiento de la Meseta Norte para comprender los procesos de neolitización, su evolución, su expansión y su distribución espacial, proyectando en los Modelos Digitales del Terreno (MDTs) de los Sistemas de Información Geográfica (SIG) todas las evidencias arqueológicas disponibles: vida cotidiana, simbólicas y funerarias. Precisamente, en este trabajo se presenta un análisis territorial diacrónico del Neolítico de la sierra de Atapuerca y la cuenca del Arlanzón (Burgos), con un SIG que incluye todos los yacimientos registrados hasta la fecha del VI al IV milenio cal BC: contextos kársticos, estructuras megalíticas, sitios al aire libre excavados y prospectados.

Los objetivos son presentar mediante un SIG la distribución territorial del Neolítico, la organización funcional del poblamiento y su articulación espacial en un área de estudio prospectada de 314 km² (10 km de radio de Cueva Mayor, sierra de Atapuerca). Para ello se exponen, también, una compilación y recalibración de todas las dataciones radiocarbónicas disponibles, los resultados del proyecto de investigación del autor (1999-2014) sobre el Holoceno del entorno de la sierra de Atapuerca, -con 10 campañas de prospecciones sistemáticas intensivas de cobertura total sobre el área de estudio de $314 \mathrm{~km}^{2}$-, una síntesis de los sitios excavados, una propuesta de la estadística multivariante para la clasificación funcional de los sitios prospectados, varias técnicas recientes de análisis espacial del SIG y test geoestadísticos inferenciales de distribución, y unas conclusiones territoriales con implicaciones para el proceso de neolitización de la Meseta Norte.
El Análisis Locacional a mesoescala realizado con el SIG o Site Catchment Analysis (estrategias de emplazamiento y factores de localización según el entorno más inmediato de los sitios) y los análisis tecno-tipológicos de los yacimientos prospectados (industrias líticas, pulimentados y cerámicas) no son objetivos del trabajo, aunque todos los análisis están incluidos en la tesis doctoral inédita del autor (Marcos, 2014). El artículo sólo se centra, por tanto, en el Análisis Territorial desde el enfoque metodológico de la Arqueología Espacial a macroescala o Arqueología del Paisaje (e.g., Hodder y Orton, 1990; Allen et al., 1990; Lock y Stancic, 1995; Wheatley y Gillings, 2002; Chapman, 2006; Marcos y Díez, 2008; David y Thomas, 2008; Conolly y Lake, 2009).

\section{CONTEXTO TERRITORIAL}

\subsection{Contexto geomorfológico y materias primas}

Las coordenadas UTM-30N-ETRS89 de la sierra de Atapuerca en el vértice geodésico del Alto de San Vicente (1084 m s.n.m.) son: X457923/Y4688926. En el contexto del norte de la península Ibérica, la sierra de Atapuerca está localizada en una encrucijada bioclimática y en una zona geoestratégica. Considerando que la sierra de Atapuerca es la última estribación cretácica del NW del Sistema Ibérico, la proximidad de la orla mesozoica vasco-cantábrica (sierra de Ubierna y sierra de Santa Casilda), el corredor de la Bureba como ruta natural, la densa red hidrográfica (ríos Arlanzón, Vena, Pico, Cueva y Salgüero), la diversidad de materiales paleozoicos, mesozoicos y cenozoicos de la sierra de la Demanda (Sistema Ibérico), y el límite de las cuencas hidrográficas del Duero y el Ebro, todo ello configura un marco geológico, geomorfológico, edáfico y paleoecológico singular para el poblamiento prehistórico. El área de estudio de $314 \mathrm{~km}^{2}$ pertenece a la cuenca del Duero, excepto el sector NE que forma parte de la cuenca del Ebro (7\% del territorio) (Fig. 1).

Otro dato de interés geológico y paleoeconómico son los afloramientos de sílex del área de estudio, de notable calidad para la tecnología prehistórica. Los nódulos de sílex neógeno de tamaño métrico aparecen en las plataformas terciarias que rodean la sierra de Atapuerca al W y SE: plataforma de Villalval-Rubena, interfluvio del Pico-Arlanzón y Los Pedernales. Los nódulos de sílex cretácico de tamaño decimétrico afloran en las cumbres de la sierra de Atapuerca (Valdecuende y Alto de San Vicente) y en vetas intrakársticas (Galería del Sílex de Cueva Mayor). Otros sílex cretácicos afloran en los cordales calizos del municipio de Arlanzón, a 9 km al SE de Cueva Mayor (Marcos, 2014). 


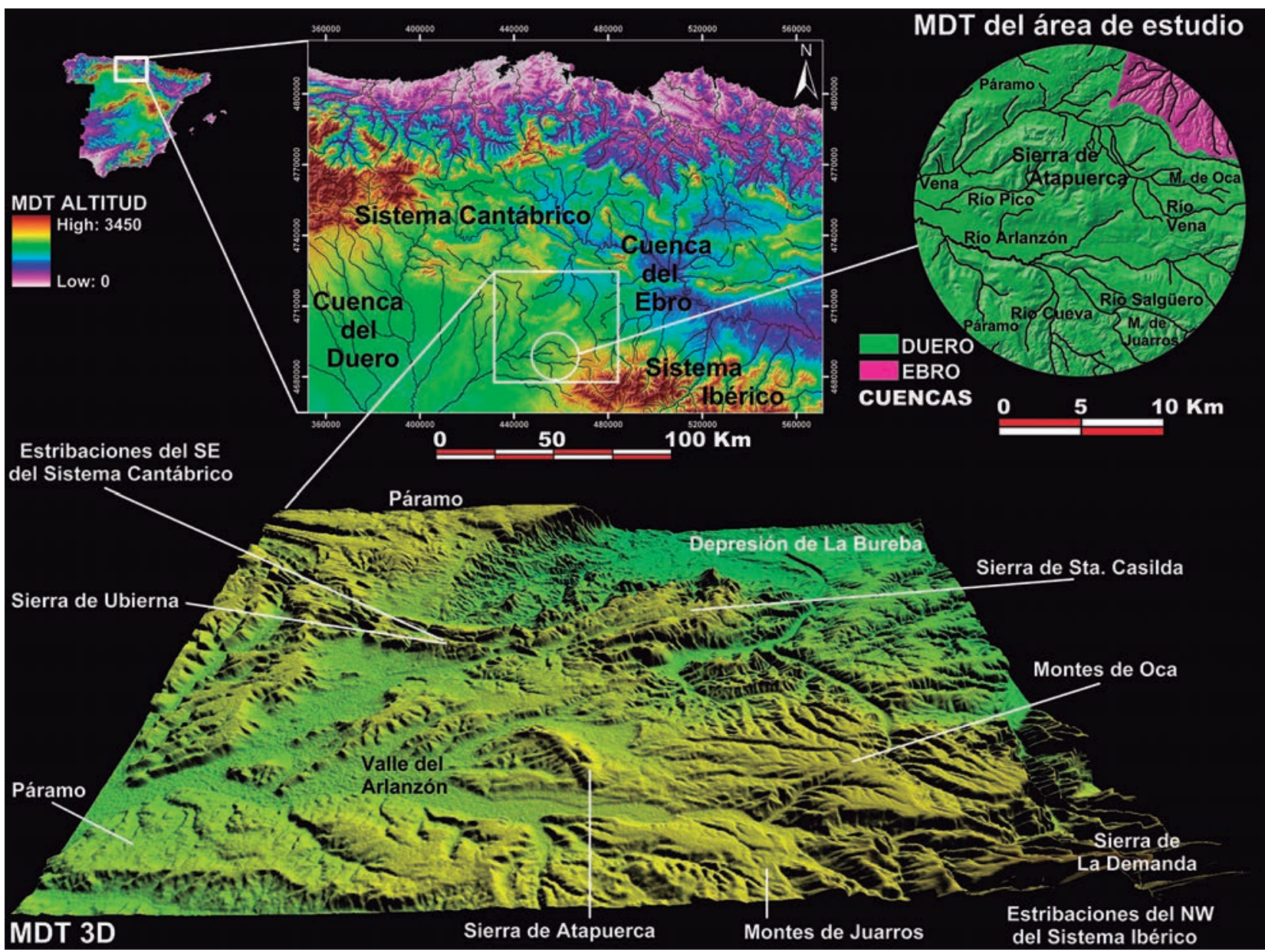

Fig. 1. Localización del área de estudio de $10 \mathrm{~km}$ de radio de Cueva Mayor (sierra de Atapuerca). La cartografía se ha construido con el SIG con varias interpolaciones de MDTs a diferentes escalas de resolución: MDT de altitud y MDT de sombra topográfica a 1:200.000 (Península Ibérica) y 1:10.000 (área de estudio). / Location of the study area in a $10 \mathrm{~km}$ radius around Mayor Cave (Sierra de Atapuerca). Several interpolations of DTMs at different resolution scales were used in the GIS mapping process: altitudinal DTM and topographic shadow DTM at 1:200,000 (Iberian Peninsula) and 1:10,000 (study area).

\subsection{Contexto paleoecológico}

A modo de síntesis, del clima templado y húmedo durante el Epipaleolítico (Preboreal, Boreal y Atlántico Antiguo), -si bien con el repunte frío del evento 8.2 ka-, se progresa a un clima más cálido y húmedo durante el Neolítico Antiguo y Medio (Atlántico Pleno), y a un clima ligeramente más frío y de aridez progresiva en el Neolítico Final y Calcolítico (Subboreal), sobre todo desde el evento $4.2 \mathrm{ka}$ cal BP. Estas tendencias paleoclimáticas han sido registradas en Cueva Mayor con análisis palinológicos, carpológicos y de composición química e isotópica de espeleotemas y estalagmitas (e.g., Martínez et al., 2010)

Otros registros palinológicos, carpológicos y antracológicos son los de la Cueva de El Mirador (e.g., Expósito et al., 2017; Rodríguez et al., 2016; Vergés et al., 2016). En el Neolítico Antiguo dominan los taxones de Pinus (pino), Quercus (robles y encinas), Corylus (avellano), Juniperus (sabinas), Castanea (castaño), Juglans (nogales), Salix (sauces), Ulmus (olmos) y Al- nus (alisos). Con el avance del Neolítico hay una alternancia de taxones mesófilos, mediterráneos y xéricos, y desde el Calcolítico hay un aumento significativo del Quercetum mixtum de robles y encinas (Quercus ilex y Quercus faginea). En conclusión, en el territorio hubo varios biotopos y ecotonos por la diversidad taxonómica, topográfica, geomorfológica, geológica y edáfica: bosques de ribera, praderas, dehesas, matorrales esclerófilos y mesófilos, sotobosques y bosques mixtos.

\subsection{Secuencia territorial de dataciones radio- carbónicas del Neolítico}

La tabla muestra todas las dataciones radiocarbónicas disponibles del Neolítico del área de estudio y su entorno más próximo, las cuales han sido recalibradas (Tabla 1). La cronología anómala de una muestra de carbón del nivel MIR24 de la Cueva de El Mirador (Beta-197386: $7030 \pm 40,6000-5810$ cal BC) debe de ser excluida de la periodización por su antigüedad, ya que excede de las dataciones más antiguas sobre muestras de vida corta 
de los sitios levantinos de la península lbérica con agriotipos y/o fenotipos domésticos (ca. 5700/5600 cal BC). También se excluye la muestra de carbón de Los Cas-
cajos-El Blanquillo (GrN-14106: 6760 \pm 130 , 5970-5480 cal BC) al producirse el mismo efecto de "madera vieja", además de una desviación estándar muy excesiva.

\begin{tabular}{|c|c|c|c|c|c|c|}
\hline Nivel & Material & Taxón & Fechas BP (14C) & $\begin{array}{c}\text { Fechas cal BC } \\
(2 \sigma / 95.4 \%)\end{array}$ & Ref. Lab. & Periodo cultural \\
\hline \multicolumn{7}{|c|}{ Cueva Mayor (Carretero et al., 2008; Ortega et al., 2008; Alday et al., 2015, 2017) } \\
\hline N7/8-(S) & Diente & n.d. & $4440 \pm 50$ & $3340-2920$ & Beta-197389 & Neolítico Final / Calcolítico \\
\hline N9-(S) & Carbón & n.d. & $4990 \pm 40$ & $3940-3660$ & Beta-184841 & Neolítico Final \\
\hline N9-(S) & Carbón & n.d. & $5230 \pm 40$ & $4230-3960$ & Beta-184842 & Neolítico Medio \\
\hline N9-(N) & Carbón & n.d. & $6070 \pm 110$ & $5290-4720$ & Beta-201762 & Neolítico Antiguo \\
\hline N9-(N) & Hueso & n.d. & $6100 \pm 50$ & $5210-4860$ & Beta-222339 & Neolítico Antiguo \\
\hline N9-(N) & Semilla & n.d. & $6140 \pm 50$ & $5220-4950$ & Beta-295768 & Neolítico Antiguo \\
\hline N9-(N) & Diente & n.d. & $6165 \pm 45$ & $5290-4990$ & Ua-32853 & Neolítico Antiguo \\
\hline N9-(N) & Sedimento & Sedimento orgánico & $6270 \pm 40$ & $5330-5080$ & Beta-222340 & Neolítico Antiguo \\
\hline N9-(N)-(base) & Carbón & n.d. & $7790 \pm 40$ & $6690-6510$ & Beta-197387 & Mesolítico \\
\hline \multicolumn{7}{|c|}{ Cueva de El Mirador (Vergés et al., 2016) } \\
\hline MIR6 & Carbón & Quercus sp. perennifolio & $4760 \pm 40$ & $3640-3380$ & Beta-153367 & Neolítico Final \\
\hline MIR8 & Carbón & Quercus sp. perennifolio & $4950 \pm 40$ & $3890-3650$ & Beta-181086 & Neolítico Final \\
\hline MIR9 & Semilla & Triticum aestivum / durum & $5050 \pm 40$ & $3960-3710$ & Beta-220912 & Neolítico Final \\
\hline MIR11 & Carbón & Quercus sp. perennifolio & $5340 \pm 50$ & $4330-4040$ & Beta-181087 & Neolítico Medio \\
\hline MIR13 & Semilla & Triticum dicoccum & $5420 \pm 40$ & $4350-4080$ & Beta-208131 & Neolítico Medio \\
\hline MIR14 & Semilla & Triticum aestivum / durum & $5470 \pm 40$ & $4440-4240$ & Beta-220913 & Neolítico Medio \\
\hline MIR16 & Carbón & Quercus sp. & $5700 \pm 70$ & $4710-4370$ & Beta-191088 & Neolítico Medio \\
\hline MIR18 & Semilla & Triticum dicoccum & $6090 \pm 40$ & $5210-4850$ & Beta-208132 & Neolítico Antiguo \\
\hline MIR19 & Carbón & Quercus sp. caducifolio & $6130 \pm 50$ & $5220-4940$ & Beta- 182040 & Neolítico Antiguo \\
\hline MIR20 & Semilla & Triticum dicoccum & $6070 \pm 50$ & $5210-4840$ & Beta-197384 & Neolítico Antiguo \\
\hline MIR21 & Carbón & Quercus sp. & $6350 \pm 40$ & $5470-5220$ & Beta-197385 & Neolítico Antiguo \\
\hline MIR22 & Semilla & Triticum aestivum / durum & $6110 \pm 40$ & $5210-4940$ & Beta-208133 & Neolítico Antiguo \\
\hline MIR23 & Semilla & Triticum dicoccum & $6300 \pm 50$ & $5460-5080$ & Beta-208134 & Neolítico Antiguo \\
\hline MIR24 & Semilla & Triticum dicoccum & $6080 \pm 40$ & $5210-4850$ & Beta-220914 & Neolítico Antiguo \\
\hline MIR24 & Carbón & Pinus sylvestris & $7030 \pm 40$ & $6000-5810$ & Beta-197386 & Neolítico Antiguo \\
\hline \multicolumn{7}{|c|}{ Alto de Rodilla (Silo funerario) (Alonso y Jiménez, 2015) } \\
\hline Silo-E-2 & Hueso & Humano & $6170 \pm 55$ & $5300-4990$ & CSIC-1967 & Neolítico Antiguo \\
\hline \multicolumn{7}{|c|}{ Alto de Rodilla (El Hoyo: Silo funerario) (Alonso y Jiménez, 2015) } \\
\hline Silo-1 & Hueso & Humano & $5400 \pm 45$ & $4350-4070$ & Ua-32289 & Neolítico Medio \\
\hline \multicolumn{7}{|c|}{ El Prado (Fosa funeraria) (Alonso y Jiménez, 2014) } \\
\hline Fosa-E-06/UE603 & Hueso & Humano & $5880 \pm 30$ & $4830-4690$ & Beta-366569 & Neolítico Antiguo \\
\hline \multicolumn{7}{|c|}{ Fuente Celada (Silo funerario) (Carmona, 2014) } \\
\hline H62-UE622 & Hueso & Humano & $6120 \pm 30$ & $5210-4960$ & UGA-7565 & Neolítico Antiguo \\
\hline \multicolumn{7}{|c|}{ Los Cascajos-El Blanquillo (Martínez, 1989) } \\
\hline NII-Estrato & Carbón & n.d. & $6760 \pm 130$ & $5970-5480$ & GrN-14106 & Neolítico Antiguo \\
\hline \multicolumn{7}{|c|}{ Molino de Arriba (Fosa funeraria) (Rojo et al., 2016) } \\
\hline Fosa-UE202 & Hueso & Humano & $6210 \pm 30$ & $5290-5060$ & KIA-41450 & Neolítico Antiguo \\
\hline \multicolumn{7}{|c|}{ Túmulo del Alto de Reinoso (Rojo et al., 2015) } \\
\hline Muestra-1 & Hueso & Humano & $4910 \pm 25$ & $3760-3640$ & MAMS-14325 & Neolítico Final \\
\hline Muestra-2 & Hueso & Humano & $4850 \pm 26$ & $3700-3540$ & MAMS-14326 & Neolítico Final \\
\hline Muestra-3 & Hueso & Humano & $4930 \pm 27$ & $3770-3650$ & MAMS-14327 & Neolítico Final \\
\hline
\end{tabular}

Tabla 1: Dataciones radiocarbónicas del Neolítico del entorno de la sierra de Atapuerca. Software y curva de calibración: OXCAL v.4.2.4 (INTCAL13) / Neolithic Radiocarbon dates from the area around Sierra de Atapuerca. Software and calibration curve: OXCAL v.4.2.4 (INTCAL13). 
La datación de la muestra de vida corta del MIR23 ( Triticum dicoccum) es la más segura para establecer el límite inferior del Neolítico territorial (Beta-208134: $6300 \pm 50$, 5460-5080 cal BC) (Vergés et al., 2016), siendo prácticamente sincrónica a las dataciones más antiguas del valle de Ambrona (Soria) (Rojo et al., 2008). En conclusión, -valorando sólo las muestras de vida corta (huesos humanos, fauna y semillas)-, el Neolítico del área de estudio muestra una secuencia continua de ocupación del territorio desde el último tercio del VI milenio hasta finales del IV milenio cal BC. Para la ubicación de los sitios se remite a los mapas de resultados. Considerando la seriación del gráfico de calibraciones, la división del Neolítico territorial por rangos temporales es la siguiente: Neolítico Antiguo (ca. 5400/5300-4600 cal BC), Neolítico Medio (ca. 4600-3800 cal BC) y Neolítico Final (ca. 3800-3000 cal BC) (Fig. 2).

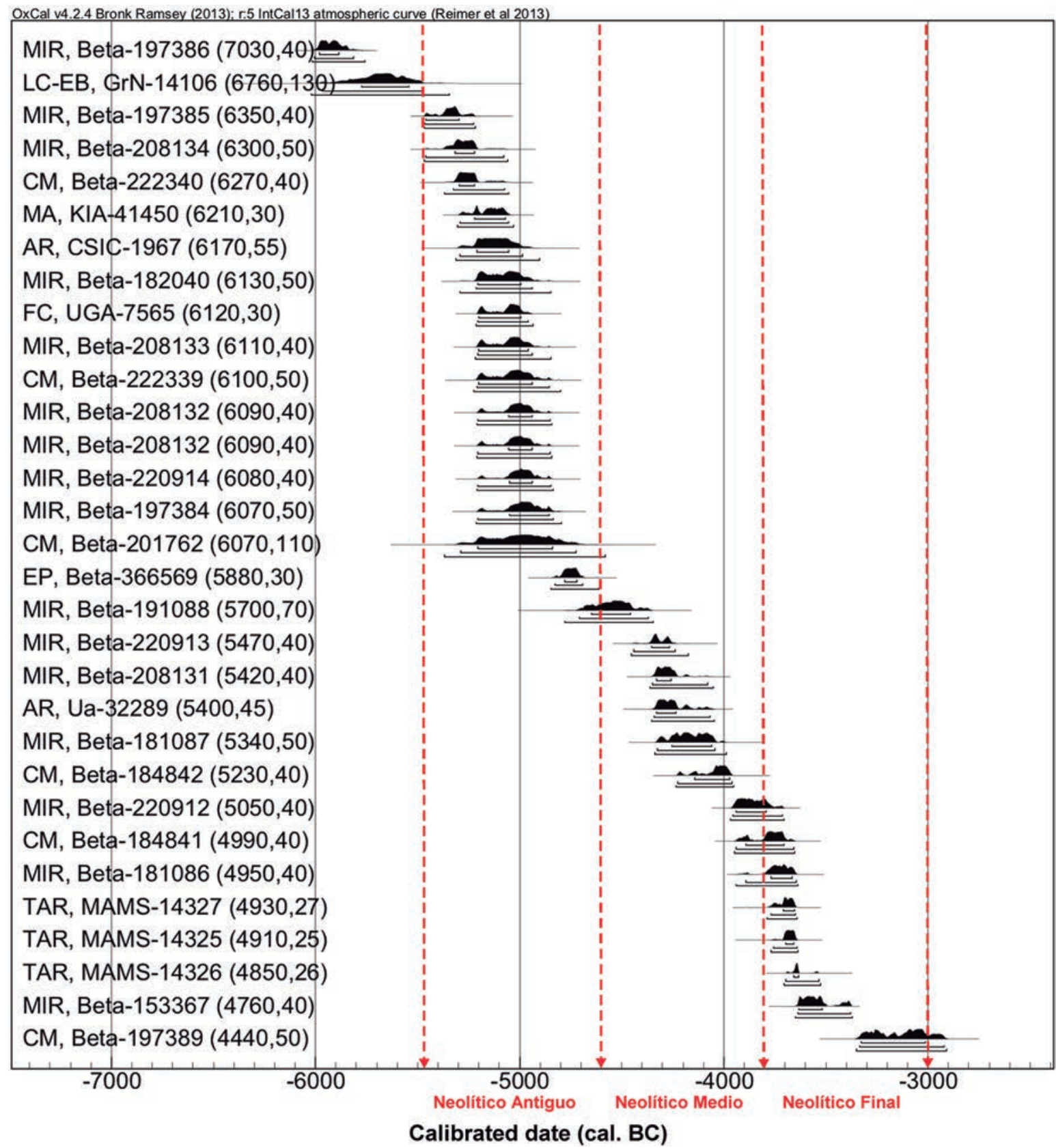

Fig. 2. Gráficos de calibración con las distribuciones de probabilidad de las dataciones radiocarbónicas del Neolítico del entorno de la sierra de Atapuerca. Siglas: Cueva Mayor (CM), Cueva de El Mirador (MIR), Alto de Rodilla y El Hoyo (AR), El Prado (EP), Los Cascajos-El Blanquillo (LC-EB), Fuente Celada (FC), Molino de Arriba (MA), Túmulo Alto de Reinoso (TAR). Software y curva de calibración: OXCAL v.4.2.4 (INTCAL13). / Calibration plots with probability distributions of the Neolithic Radiocarbon dates from the area around Sierra de Atapuerca. Site Codes. Software and calibration curve: OXCAL v.4.2.4 (INTCAL13). 


\section{MATERIALES Y MÉTODOS}

\subsection{Las prospecciones sistemáticas del entor- no de la sierra de Atapuerca (1999-2007)}

El proyecto de investigación del Holoceno dirigido por el autor está basado en 10 campañas de prospecciones sistemáticas intensivas de un mes cada una: 8 campañas entre los años 1999 y 2003, más 2 campañas en el 2007.

\subsubsection{Las prospecciones sistemáticas intensivas de cobertura total (1999-2003)}

El objetivo de las 8 primeras campañas de prospección era descubrir el mayor número posible de yacimientos prehistóricos del Pleistoceno y Holoceno en el área de estudio de 314 km² (10 km de radio de Cueva Mayor) (Navazo, 2006; Marcos, 2006, 2014). Estudiar los patrones de asentamiento requería de un método de prospección sistemática que no obviase ninguna evidencia arqueológica superficial, recogiendo todos los artefactos líticos y cerámicos visibles en la banda de terreno de cada prospector para realizar inferencias tecnológicas y funcionales de los sitios con modelos matemáticos de clasificación computerizada.

En la planificación se eligió el método «sistemático intensivo de cobertura total» (registro absoluto del área de estudio y no muestreos parciales ni zonas de potencialidad arqueológica), por ser el menos sesgado para el estudio de los patrones de asentamiento, proporcionando datos completos al minimizar el riesgo de pasar por alto yacimientos muy pequeños en la superficie del terreno (e.g., Fish y Kowalewski, 1990). El concepto de «sistemático» significa que siempre se aplica la misma batería de prospectores con una formación unidireccional. El concepto de «intensivo» es la distancia entre los prospectores; y, el de «cobertura total», tanto a la cantidad de terreno prospectado del área de estudio (100\%), -diferencia radical con respecto a los métodos de muestreo ( $v$. Renfrew y Bahn, 1993)-, como a la probabilidad de no detectar un sitio en condiciones de alta visibilidad.

En las 8 campañas de prospección se prospectó todo el territorio de $314 \mathrm{~km}^{2}$ con 10 prospectores diarios cualificados y separados en una batería a intervalos regulares de 15-20 m (alta intensidad). Las prospecciones fueron exhaustivas y de alta visibilidad, porque más del $80 \%$ del territorio está formado por campos de cultivos recién roturados en marzo y noviembre, los meses de ejecución. En cada prospección se demarcaba un área de intervención sobre los mapas que era cuadriculada con una rejilla de $250 \mathrm{~m}$ de celda y numerada con caracteres alfanuméricos. Todos los artefactos eran introducidos en bolsas herméticas etiquetadas con el municipio, la localidad, el topónimo, el nombre del sitio, el n. ${ }^{\circ}$ de cuadrícula, el $n .^{\circ}$ de polígono y el $n .^{\circ}$ de parcela agrícola de los planos parcelarios (1:5000). Con los avances y paradas de los prospectores al en- contrar artefactos, los yacimientos eran dibujados en los mapas sobre el terreno por el coordinador, marcando con puntos la ubicación de los artefactos según la indicación de los prospectores y con la delimitación gráfica de las dispersiones de artefactos, las subzonas de concentración de artefactos de cada dispersión y los grandes vacíos entre las dispersiones. Asimismo, se tomaron coordenadas de todos los sitios con el GPS.

El trabajo de laboratorio consistió en la limpieza y siglado de unas 15.000 piezas líticas y cerámicas distribuidas entre 190 yacimientos del Pleistoceno y Holoceno. Además de estos sitios, descubrimos otras zonas con artefactos aislados calificados en la bibliografía de zonas «offsite», «non site» o de «background noise» (e.g., Gallant, 1986; Bintliff, 2000). La posterior revisión de estas zonas con una inspección y visibilidad más intensa reportó 11 yacimientos nuevos con las dos campañas de prospecciones sistemáticas intensivas del 2007 ( $v$. infra). Todos los yacimientos fueron registrados en el «Inventario Arqueológico de Castilla y León» (IACYL). En conclusión, el cómputo global de yacimientos descubiertos es de cerca de 200 sitios del Pleistoceno y Holoceno, de los cuales 168 son de la Prehistoria Reciente (Marcos, 2014). De acuerdo con la bibliografía, en este estudio los conceptos de «yacimiento», "sitio» y "dispersión de artefactos» son equivalentes cuando las dispersiones de artefactos siguen los siguientes criterios:

1) A escala territorial (macroescala) todas las «dispersiones de artefactos» son concentraciones significativas de piezas cuyos límites pueden ser identificados y mapeados en las prospecciones. Estas pequeñas dispersiones de artefactos con límites bien definidos son los «yacimientos» o «sitios». 2) Los artefactos aislados con grandes distancias entre ellos (>50 m), y/o que están muy separados de otras «dispersiones de artefactos» por grandes vacíos significativos de piezas, son considerados como «hallazgos aislados", "offsite» o «background noise». 3) Por el contrario, todas las «dispersiones de artefactos» de los «yacimientos» muestran una continuidad espacial entre los artefactos, con asociaciones significativas de piezas sin grandes distancias entre ellas ( $\pm 25 \mathrm{~m}$ ). 4) Todos los «yacimientos» o «sitios» están separados de otros «yacimientos» por grandes distancias con vacíos significativos de artefactos. 5) A microescala, cada «yacimiento» puede contener dentro de la propia «dispersión de artefactos» una o varias subzonas con mayor densidad de piezas denominada «concentración de artefactos», la cual sugiere la ubicación original del «sitio». 6) Las «concentraciones de artefactos» suelen mostrar unas altas densidades de piezas ( \pm 5 piezas $/ 10 \mathrm{~m}^{2}$ ), y las de la Prehistoria Reciente suelen estar muy asociadas a los manchones oscuros y/o cenicientos del terreno de facies edáficas orgánicas, los cuales suelen ser el resultado de la alteración agrícola de las estructuras negativas del subsuelo: los «campos de hoyos» (silos, hoyos, fosas, zanjas, zonas de estabulación y fondos 
de cabañas). 7) Los «yacimientos» pueden contener diferentes cantidades de piezas, densidades y extensiones, dependiendo de factores geoarqueológicos y de la función de cada sitio, de su duración e intensidad.

\subsubsection{Las prospecciones sistemáticas intensivas de los sitios del Holoceno (2007)}

En el 2007 se ejecutaron dos nuevas campañas de prospecciones sistemáticas intensivas sobre las dispersiones de artefactos de los sitios del Holoceno, con un triple objetivo. Primero, se requería precisar la cronología de varios sitios con una recogida selectiva de «fósiles directores» de industria lítica y cerámica decorada. Segundo, se pretendía confirmar la presencia de cerámicas en aquellos sitios donde estaban ausentes al incrementar la intensidad de las prospecciones con una batería de 6 prospectores a intervalos regulares de 5 metros, con resultados muy positivos. En tercer lugar, al ser las prospecciones de muy alta intensidad y alta visibilidad, -meses de marzo y noviembre-, se revisaron todos los límites de las dispersiones y concentraciones de artefactos para cartografiarlas con mayor precisión en el SIG (<1:1000), efectuando múltiples correcciones en los planos parcelarios (1:5000) superpuestos a las ortofotografías aéreas georreferenciadas de alta resolución (PNOA, $25 \mathrm{~cm}$ de celda). Del mismo modo, con las prospecciones sistemáticas a microescala del 2007 descubrimos nuevas concentraciones de artefactos asociadas a varios manchones oscuros del terreno de horizontes edáficos orgánicos, los cuales, junto con los descubiertos en las campañas anteriores, también fueron delimitados en las ortofotografías aéreas.

A continuación, toda la información fue digitalizada y tabulada en el SIG, generando cerca de 200 mapas georreferenciados con las dispersiones y concentraciones de artefactos (Marcos, 2014). Para la creación de los mapas se implementó en el SIG un mosaico ráster de 56 ortofotografías aéreas georreferenciadas (PNOA / UTM-30N-ED50, $25 \mathrm{~cm}$ de celda), 20 capas vectoriales de curvas de nivel topográficas con equidistancia de 5 $\mathrm{m}$ de altitud (escala 1:10.000) y 20 capas vectoriales de curvas directoras topográficas (escala 1:10.000) del Instituto Geográfico Nacional (IGN). Después se procedió a la digitalización de los polígonos vectoriales de las dispersiones y concentraciones de artefactos según los resultados del trabajo de campo. En otro proceso, con los algoritmos del software ArcGIS 9 (Arclnfo Desktop) se calcularon las coordenadas del punto-centroide de cada sitio según los polígonos vectoriales y la extensión en hectáreas de cada yacimiento. Este punto-centroide vectorial de cada sitio es proyectado en los MDTs para los análisis espaciales y geoestadísticos del SIG.

\subsubsection{Otras intervenciones arqueológicas}

Para georreferenciar y digitalizar los yacimientos de otras intervenciones realizadas en el área de estu- dio de $314 \mathrm{~km}^{2}$ (cuevas, sitios y estructuras megalíticas) ( $v$. infra) fueron recopiladas todas las referencias bibliográficas, fichas del IACYL y todos los informes técnicos de los sitios prospectados y/o excavados por la Arqueología de Gestión. Asimismo, hemos contrastado todos los yacimientos en las prospecciones del 2007 y en años posteriores (Marcos, 2014), aplicando los mismos procesos cartográficos de proyección, escala y resolución, creando una base de datos geoespacial de SIG (GDB) con todos los sitios del Holoceno registrados hasta la fecha

\subsection{Sistema de Información Geográfica (SIG) y Análisis Espacial}

\subsubsection{Bases de datos geoespaciales (GDBs) y Modelos Digitales del Terreno (MDTs)}

La base del SIG fue la digitalización y georreferenciación (UTM-30N-ED50) de todos los sitios de la Prehistoria Reciente (>200 sitios) con el software ArcGIS 9 (Arclnfo Desktop), con tres grandes capas vectoriales: polígonos de las dispersiones y concentraciones de artefactos, y puntos-centroides de los sitios. Cada capa tiene vinculada una GDB en lenguaje relacional SQL (Structured Query Language), donde fueron editados todos los atributos alfanuméricos de cada sitio: identificador (ID), geometría, coordenadas (XYZ), nombre del sitio, localidad, municipio, extensión, materiales, periodos, fases, función, etc. Otras bases de datos conectadas a las GDBs del SIG con el mismo ID por cada yacimiento son las del software estadístico SPSS. La capa vectorial de puntos-centroides de los sitios contiene, por ejemplo, una GDB con la clasificación funcional de los sitios según los análisis estadísticos.

Los MDTs son otros archivos del software ArcGIS, en este estudio en el formato de datos ráster Arc/Info Grid. El formato ráster es un modelo de representación digital de los datos espaciales basado en una estructura de celdas o píxeles de igual tamaño y organizados en una matriz de filas y columnas. A diferencia del formato vectorial (puntos, líneas y polígonos, los últimos formados por vértices y arcos), la matriz de celdas del formato ráster cubre toda la superficie del mapa y cada celda tiene un valor registrado en su respectiva GDB. En los modelos ráster cuantitativos continuos cada celda de la matriz tiene tabulada un valor numérico expresado con decimales para representar la distribución espacial de una variable temática basada en una escala de valores: elevación, pendiente, orientación, sombra topográfica, etc.

Los MDTs del trabajo han sido construidos con el ArcGIS 9, aplicando los módulos y herramientas del Análisis Espacial: 3D Analyst, Spatial Analyst, Geostatistical Analyst y GIS Raster Calculator. Los MDTs son de alta resolución (MDT de Elevaciones y MDT de Sombra topográfica acimutal y angular, $10 \mathrm{~m}$ de celda), y han sido creados por el autor desde una cartografía 
vectorial restituida (1:10.000) con las técnicas de interpolación de superficies continuas: TIN, IDW, Kriging, etc. En este caso, la interpolación del MDT de Elevaciones fue realizada con la técnica TIN (Triangular Irregular Network) por ser la técnica más idónea para respetar los datos altimétricos de origen de la cartografía vectorial restituida del Plan Nacional de Ortofotografía Aérea (PNOA), la cual consta de 256 capas vectoriales para cubrir el área de estudio: 64 de hidrografía, 64 de curvas de nivel, 64 de curvas directoras y 64 de puntos de cota con sus respectivas GDBs. Posteriormente, del modelo TIN se generó un MDT de Elevaciones en formato ráster, al ser un formato de datos mucho más ligero, y del MDT de Elevaciones se derivó el MDT de Sombra topográfica acimutal y angular.

EI MDT de Sombra topográfica acimutal y angular a escala 1.10.000 (10 m de celda) es la base cartográfica en este trabajo para la proyección espacial de los yacimientos. Otros MDTs de muy alta resolución del proyecto, sólo operativos para zonas pequeñas del territorio, han sido interpolados a escala 1.5000 (5 m de celda) con cartografía vectorial restituida (PNOA), y a escala 1.1000 (1 $\mathrm{m}$ de celda) con las bases de datos LiDAR del IGN.

\subsubsection{Técnicas geoestadísticas del Análisis Espacial}

En las técnicas geoestadísticas se aplican varios métodos cuantitativos e inferenciales del SIG para el análisis espacial de distribuciones de puntos vectoriales (yacimientos) y de capas ráster: Average Nearest Neighbor Test, Multi-Distance Spatial Cluster Analysis (Función $\mathrm{K}$ de Ripley), Kernel Density Analysis, Correlación espacial ráster multivariante (r de Pearson), Autocorrelación espacial (I de Moran), High/Low Clustering (G general de Getis-Ord) y Hot Spot Analysis (Gi* de Getis-Ord). Estas técnicas están implementadas en el software ArcGIS (Spatial Analyst \& Spatial Statistics Tools). En los resultados se describen las técnicas, objetivos y parámetros aplicados, remitiendo para mayor comprensión a varios autores (e.g., Ripley, 1981; Hodder y Orton, 1990; Allen et al., 1990; Getis y Ord, 1996; Lock y Stancic, 1995; Wheatley y Gillings, 2002; Diggle, 2003; Marcos y Díez, 2008; Conolly y Lake, 2009; Mitchell, 2012).

\subsection{Análisis tecno-tipológico y atribución cro- no-cultural}

En el análisis sistemático de las industrias líticas de las prospecciones se aplicaron varios métodos (Marcos, 2014): identificación de las materias primas (autóctonas y alóctonas), análisis de las cadenas de producción lítica con los caracteres morfotécnicos de las categorías estructurales del Sistema Lógico Analítico (SLA) (v. Carbonell y Rodríguez, 2002), Tipometría de Bagolini de los productos de talla completos, y la sistematización de los útiles retocados con la Tipología Analítica de Laplace de 1972 ampliada con los grupos tipológicos de la Prehistoria Reciente (v. Merino, 1994). Todos los análisis estadísticos se realizaron con el software SPSS.

La atribución crono-cultural está basada, por tanto, en múltiples criterios coherentes de la tecnología y la tipología lítica (estrategias de explotación, tipos de núcleos, tipometría, caracteres morfotécnicos de los productos, producción laminar en los productos de talla y útiles retocados, tratamiento térmico, lustres de cereal, caracteres morfotécnicos de los retoques, grupos tipológicos de útiles, morfotipos, etc.); en los criterios de presencia y ausencia de los típicos «fósiles directores» de los diferentes periodos de la Prehistoria Reciente (microlitos geométricos, tipos de puntas de flecha, tipos de piezas de hoz, etc.); en la clasificación por pátinas de las industrias líticas; en la presencia de los utensilios pulimentados (hachas, azuelas, cinceles y gubias); y, en los criterios de presencia y ausencia de las cerámicas según las tipologías, técnicas y sintaxis estilísticas de las decoraciones. Las industrias líticas y las cerámicas del Neolítico, Calcolítico y Edad del Bronce han sido contrastadas con las de los yacimientos excavados de la Meseta Norte y del Alto Ebro, destacando como paralelos del área de estudio los materiales datados de los niveles de Cueva Mayor y Cueva de El Mirador.

\subsection{Análisis funcional de los sitios y estadísti- ca multivariante}

La función de un yacimiento de prospección no puede ser inferida de la ubicación geográfica del sitio, ya que por ejemplo puede haber espacios habitacionales tanto en alto, en laderas como en los fondos de valle. En consecuencia, la función de los sitios sólo puede ser inferida del análisis de los restos materiales derivados de las actividades socioeconómicas. Los yacimientos prospectados se clasificaron en «poblados» y «sitios complementarios» según los análisis de las industrias líticas y cerámicas, con unos criterios cuantitativos y cualitativos basados en el equilibrio, desequilibrio, integridad o fragmentación de las cadenas de producción lítica, la variedad de materias primas, la homogeneidad o heterogeneidad tipométrica y morfotécnica, la diversidad funcional de los grupos tipológicos y morfotipos de los utensilios retocados, además de la presencia o ausencia de una vajilla doméstica (vasos, cuencos y ollas) con diversidad de tamaños y grosores. La presencia de molinos, molederas y manchones oscuros del terreno asociados a los artefactos también fue valorada en la clasificación funcional.

En la tabla se sintetizan los criterios diagnósticos y las tendencias generales para la clasificación funcional de los sitios (Tabla 2), aunque en las prospecciones no necesariamente deban de registrarse todos los criterios por los posibles sesgos muestrales, -caso de la alta fragmentación de las cerámicas por el laboreo agrícola mecanizado-, y por la amplia variedad de ocupaciones posibles. 


\begin{tabular}{|c|c|c|c|}
\hline \multirow{2}{*}{$\begin{array}{l}\text { Criterios diagnósticos } \\
\text { (industrias líticas y cerámicas) }\end{array}$} & \multicolumn{3}{|c|}{ Grupos funcionales y tendencias generales } \\
\hline & $\begin{array}{l}\text { Poblados o espacios } \\
\text { habitacionales }\end{array}$ & $\begin{array}{l}\text { Sitios complementarios } \\
\text { (recurrentes y efímeros) }\end{array}$ & $\begin{array}{l}\text { Talleres de sílex } \\
\text { sobre afloramientos }\end{array}$ \\
\hline Cantidad de artefactos & $\begin{array}{l}\text { Alta, dependiendo de la duración e } \\
\text { intensidad de las ocupaciones } \\
\text { (estables y estacionales) }\end{array}$ & $\begin{array}{l}\text { Baja, dependiendo del carácter recurrente } 0 \\
\text { esporádico de las ocupaciones }\end{array}$ & Muy alta \\
\hline Densidad de artefactos & $\begin{array}{l}\text { Alta, dependiendo de la duración e } \\
\text { intensidad de las ocupaciones } \\
\text { (estables y estacionales) }\end{array}$ & $\begin{array}{l}\text { Baja, dependiendo del carácter recurrente } 0 \\
\text { esporádico de las ocupaciones }\end{array}$ & Muy alta \\
\hline Afloramientos de silex & Presentes 0 ausentes & Presentes 0 ausentes & Presentes \\
\hline Materias primas autóctonas & Mayor variedad & Menor variedad & $\begin{array}{l}\text { Sin variedad por el afloramiento de sílex o } \\
\text { muy escasa }\end{array}$ \\
\hline Materias primas alóctonas & Mayor variedad 0 ausentes & Menor variedad 0 ausentes & Ausentes \\
\hline $\begin{array}{l}\text { Cadena operativa de producción lítica } \\
\text { autóctona }\end{array}$ & Completa y equilibrada & Completa o incompleta, pero desequilibrada & $\begin{array}{l}\text { Completa y muy desequilibrada por el } \\
\text { predominio de los productos de talla }\end{array}$ \\
\hline Cadena operativa de producción lítica alóctona & $\begin{array}{l}\text { Ausente o incompleta, pero muy } \\
\text { desequilibrada por el predominio } \\
\text { de los útiles retocados alóctonos }\end{array}$ & $\begin{array}{l}\text { Ausente o incompleta, pero muy desequilibrada por } \\
\text { el predominio de los útiles retocados alóctonos }\end{array}$ & Ausente \\
\hline Núcleos (BN1GE y BN2GE) & $\begin{array}{l}\text { Presentes, con alta diversidad de tipos, } \\
\text { técnicas y estrategias de talla } \\
\text { (láminas y lascas) }\end{array}$ & $\begin{array}{l}\text { Presentes o ausentes, con baja diversidad de tipos, } \\
\text { técnicas y estrategias de talla (láminas y lascas) }\end{array}$ & $\begin{array}{l}\text { Presentes, con muy baja diversidad de } \\
\text { tipos, técnicas y estrategias de talla. } \\
\text { Predominio de la talla de lascas }\end{array}$ \\
\hline Productos de talla (BP y BPF) & $\begin{array}{l}\text { Presentes, con alta diversidad de formatos, } \\
\text { técnicas y estrategias de talla (láminas y } \\
\text { lascas). Alta diversidad de talones }\end{array}$ & $\begin{array}{l}\text { Presentes o ausentes, con baja diversidad de } \\
\text { formatos, técnicas y estrategias de talla (láminas y } \\
\text { lascas). Baja diversidad de talones }\end{array}$ & $\begin{array}{l}\text { Presentes, con muy alta diversidad de } \\
\text { formatos y baja diversidad de técnicas y } \\
\text { estrategias de talla. Muy baja diversidad } \\
\text { de talones }\end{array}$ \\
\hline Útiles retocados (BN2GC y BN1GC) & $\begin{array}{l}\text { Presentes, con alta diversidad de formatos, } \\
\text { técnicas y estrategias de tallla (laminas y } \\
\text { lascas) y gran diversidad de retoques }\end{array}$ & $\begin{array}{c}\text { Presentes o ausentes, con baija diversidad de } \\
\text { técnicas y estrategias de talla a láminas y lascas) y } \\
\text { baja diversidad de retoques }\end{array}$ & $\begin{array}{c}\text { Presentes o ausentes, con muy baja } \\
\text { diversidad de técnicas y estrategias de talla a } \\
\text { (láminas y lascas) y muy baja diversidad } \\
\text { de retoques }\end{array}$ \\
\hline Productos corticales ( $1^{\text {a }}$ fase de explotación) & Presentes o ausentes. Baja proporción & Presentes 0 ausentes. Baja o muy baja proporción & Presentes. Muy alta proporción \\
\hline $\begin{array}{l}\text { Productos semicorticales } \\
\text { ( } 2^{\mathrm{a}} \text { fase de explotación) }\end{array}$ & Presentes o ausentes. Moderada proporción & Presentes o ausentes. Baja o muy baja proporción & Presentes. Muy alta proporción \\
\hline Productos internos ( $3^{\text {a }}$ fase de explotación) & Presentes. Alta proporción & Presentes. Alta o muy alta proporción & Presentes. Baja proporción \\
\hline $\begin{array}{l}\text { Diversidad tipométrica de productos de talla } \\
\text { completos (Módulos de Bagolini) }\end{array}$ & $\begin{array}{c}\text { Alta diversidad } \\
\text { tecnocomplejo de lascas y laminillas) }\end{array}$ & $\begin{array}{c}\text { Baja diversidad } \\
\text { (tecnocomplejo de lascas y laminillas) }\end{array}$ & $\begin{array}{l}\text { Muy alta diversidad } \\
\text { (micro, meso y macro) }\end{array}$ \\
\hline $\begin{array}{l}\text { Diversidad tipológica de útiles retocados } \\
\text { (BN2GC y BN1GC) }\end{array}$ & $\begin{array}{l}\text { Alta diversidad de morfotipos, representativa } \\
\text { de diferentes actividades económicas } \\
\text { domésticas }\end{array}$ & $\begin{array}{l}\text { Baja diversidad de morfotipos, representativa de } \\
\text { actividades especializadas recurrentes o efímeras }\end{array}$ & $\begin{array}{l}\text { Muy baja o nula diversidad de morfotipos } \\
\text { retocados, pero dependiendo de la dura- } \\
\text { ción del taller }\end{array}$ \\
\hline $\begin{array}{l}\text { Diversidad tipológica de grupos de útiles } \\
\text { retocados (BN2GC y BN1GC) }\end{array}$ & $\begin{array}{l}\text { Alta diversidad de grupos, representativa } \\
\text { de diferentes actividades económicas } \\
\text { domésticas }\end{array}$ & $\begin{array}{l}\text { Baja diversidad de grupos, representativa de activi- } \\
\text { dades especializadas recurrentes o efimeras }\end{array}$ & $\begin{array}{l}\text { Muy baja o nula diversidad de grupos, pero } \\
\text { dependiendo de la duración del taller }\end{array}$ \\
\hline Complejidad tecnológica y tipológica & $\begin{array}{l}\text { Mayor compleijdad tecnológica y tipológica, } \\
\text { con gran diversidad morfotécnica, } \\
\text { morfofuncional y morfopotencial }\end{array}$ & $\begin{array}{l}\text { Menor complejidad tecnológica y tipológica, } \\
\text { con moderada diversidad morfotécnica, } \\
\text { morfofuncional y morfopotencial }\end{array}$ & $\begin{array}{l}\text { Escasa complejidad tecnológica y tipológi- } \\
\text { ca, con muy baja diversidad morfotécnica, } \\
\text { morfofuncional y morfopotencial }\end{array}$ \\
\hline $\begin{array}{l}\text { Técnicas y estrategias de talla predetermina- } \\
\text { das: piramidales, prismáticas, ortogonales, etc. }\end{array}$ & $\begin{array}{l}\text { Más elaboradas y predeterminadas, } \\
\text { con mayor diversidad }\end{array}$ & $\begin{array}{l}\text { Menos elaboradas y predeterminadas, } \\
\text { con menor diversidad }\end{array}$ & $\begin{array}{c}\text { Predominio de estrategias de talla informes } \\
\text { y unifaciales }\end{array}$ \\
\hline Producción laminar & $\begin{array}{l}\text { Alta representación en núcleos, productos } \\
\text { de talla y útiles retocados }\end{array}$ & $\begin{array}{c}\text { Moderada representación en núcleos, productos de } \\
\text { talla y útiles retocados }\end{array}$ & $\begin{array}{l}\text { Muy baja representación en núcleos, } \\
\text { productos de talla y útiles retocados }\end{array}$ \\
\hline Tratamiento térmico laminar & $\begin{array}{c}\text { Mayor presencia en núcleos, productos de } \\
\text { talla y útiles retocados }\end{array}$ & $\begin{array}{l}\text { Menor presencia en núcleos, productos de talla y } \\
\text { útiles retocados }\end{array}$ & $\begin{array}{c}\text { Ausente, por lo general en núcleos, produc- } \\
\text { tos de talla y útiles retocados }\end{array}$ \\
\hline $\begin{array}{l}\text { Productos de talla con huellas de uso } \\
\text { (láminas y lascas) }\end{array}$ & $\begin{array}{l}\text { Alta representación de láminas simples y } \\
\text { lascas con huellas de uso }\end{array}$ & Alta representación de lascas con huellas de uso & $\begin{array}{l}\text { Ausentes o muy baja representación de } \\
\text { huellas de uso }\end{array}$ \\
\hline Artefactos pulimentados & $\begin{array}{l}\text { Presentes o ausentes. Varios tipos y tama- } \\
\text { ños (hachas, azuelas, cinceles y gubias) }\end{array}$ & $\begin{array}{l}\text { Presentes o ausentes. Menor variedad de tipos } \\
\text { (hachas y azuelas) }\end{array}$ & Ausentes o escasamente representados \\
\hline Percutores y mazas & Presentes & Presentes 0 ausentes & Presentes \\
\hline Molinos y molederas & Presentes 0 ausentes & Ausentes, por lo general & Ausentes, por lo general \\
\hline Cerámicas: cantidad de recipientes & $\begin{array}{l}\text { Mayor cantidad de cerámicas. Presentes } \\
0 \text { ausentes por la alta fragmentación del } \\
\text { laboreo agrícola mecanizado }\end{array}$ & $\begin{array}{l}\text { Pocas cerámicas o ausentes. } \\
\text { Presentes o ausentes por la alta fragmentación } \\
\text { del laboreo agrícola mecanizado }\end{array}$ & Ausentes, por lo general \\
\hline Cerámicas: tipología de formas y tamaños & $\begin{array}{l}\text { Mayor diversidad tipológica de formas, } \\
\text { grosores y volúmenes. } \\
\text { Presencia de recipientes grandes }\end{array}$ & $\begin{array}{l}\text { Escasa diversidad tipológica de formas, } \\
\text { grosores y volúmenes. Recipientes pequeños }\end{array}$ & Ausentes, por lo general \\
\hline $\begin{array}{l}\text { Manchones oscuros del terreno de horizontes } \\
\text { edáficos orgánicos }\end{array}$ & $\begin{array}{l}\text { Presentes, por lo general, yen muchos } \\
\text { casos asociados a artefactos }\end{array}$ & Presentes 0 ausentes & Ausentes, por lo general \\
\hline
\end{tabular}

Tabla 2: Criterios diagnósticos para la clasificación funcional de los yacimientos de prospección / Diagnostic criteria applied for the functional classification of surveyed sites. 
Posteriormente, se realizó un Análisis Factorial Discriminante (AFD), -también denominado como Análisis de la Función Discriminante-, para validar la clasificación funcional con 11 variables por cada sitio (Tabla 3). La cantidad de fragmentos cerámicos no se incluye como variable cuantitativa por no ser representativa en las prospecciones de la cantidad de recipientes completos, además de que la alta fragmentación de las vajillas por el laboreo agrícola mecanizado impide cualquier estimación. El AFD se aplicó con el SPSS para contrastar el grado de concordancia de la clasificación funcional bipartita («poblados» y «sitios complementarios»), -basada en criterios cuantitativos y cualitativos-, con la clasificación automática cuantitativa que genera el modelo predictivo, mediante el análisis de las relaciones entre la variable categórica (criterio) con las 11 variables independientes (predictoras). Por consiguiente, en la matriz de sitios y variables la variable categórica (criterio) es la clasificación funcional.

El AFD calcula la combinación lineal de variables independientes que mejor discrimina a los grupos funcionales incluidos. La mejor función discriminante es aquella que maximiza la varianza entre los grupos frente a la varianza intergrupal (e.g., Mallo, 1985; Hair et al., 1999). EI AFD genera tantos factores o funciones discriminantes como grupos menos uno (Ng-1), necesitando dos factores para producir un gráfico factorial. Como sólo hay dos grupos funcionales se incluyó un tercer grupo en la variable categórica (criterio) denominado «gran taller de sílex». Este grupo sólo está representado por Los Pedernales, un yacimiento muy atípico que es el único representante de uno de los grupos del dendrograma del Análisis Cluster Jerárquico realizado con las mismas variables (v. Marcos, 2014). La función del yacimiento, - ubicado sobre un gran afloramiento de sílex neógeno-, está acreditada por la gran cantidad de piezas líticas de talla de su superficie, con gran diversidad tipométrica y con abundancia de productos corticales.

\section{CUEVAS, TÚMULOS, SILOS FUNERARIOS Y OTROS SITIOS NEOLÍTICOS}

En el área de estudio se realizaron excavaciones sistemáticas en varias cuevas, túmulos megalíticos, silos funerarios y asentamientos de exterior del Neolítico (VI-IV milenio cal BC). Todos los sitios están incluidos en el SIG ( $v$. Mapas de resultados). A continuación, por espacio, sólo se describe una breve síntesis de los sitios, remitiendo a la bibliografía y a la tabla de dataciones.

Cueva Mayor: Es la principal entrada al sistema kárstico de Atapuerca junto con la Cueva del Silo. En la estratigrafía de unos $10 \mathrm{~m}$ de profundidad (11 niveles) hay potentes registros habitacionales del Neolítico a la Edad del Bronce. Una de las dataciones del Neolítico Antiguo es de las más antiguas de la Meseta Norte (Beta-222340: 6270 \pm 40, 5330-5080 cal BC). Los restos arqueológicos son muy abundantes: industrias líticas, industrias óseas, cerámicas, adornos de hueso, conchas, restos humanos, fauna salvaje, fauna doméstica, restos antracológicos, carpológicos y palinológicos (e.g., Apellániz y Uríbarri, 1976; Apellániz y Domingo, 1987; Carretero et al., 2008; Ortega et al., 2008; Ortega, 2009; Alday et al., 2009, 2017).

Galería del Sílex: En este espacio intrakárstico hay varios enterramientos en posición secundaria, estructuras circulares, silos de almacenaje, fuegos de alumbrado, una estructura de arcilla para la acumulación de líquidos, cerámicas del Neolítico a la Edad del Bronce, industria lítica, industria ósea, fauna y varios paneles de grabados y pinturas rupestres que motivaron la

\begin{tabular}{|c|c|c|}
\hline $\mathbf{N}^{\circ}$ & Variables predictoras (AFD) & Categorías estructurales implicadas (SLA) \\
\hline 1 & $N^{\circ}$ de efectivos líticos & $\mathrm{BN} 1 \mathrm{GE}+\mathrm{BN2GE}+\mathrm{BP}+\mathrm{BPF}+\mathrm{BN2GC}+\mathrm{BN1GC}$ \\
\hline 2 & $N^{\circ}$ de productos de talla & $\mathrm{BP}+\mathrm{BPF}$ \\
\hline 3 & № de núcleos & BN1GE + BN2GE \\
\hline 4 & $N^{\circ}$ de útiles retocados & $B N 2 G C+B N 1 G C$ \\
\hline 5 & № de productos corticales (cara dorsal): $1^{a}$ fase de explotación & $\mathrm{BP}+\mathrm{BPF}+\mathrm{BN} 2 \mathrm{GC}+\mathrm{BN} 2 \mathrm{GE}$ \\
\hline 6 & $\mathrm{~N}^{\circ}$ de productos semicorticales (cara dorsal): $2^{\mathrm{a}}$ fase de explotación & $\mathrm{BP}+\mathrm{BPF}+\mathrm{BN} 2 \mathrm{GC}+\mathrm{BN} 2 \mathrm{GE}$ \\
\hline 7 & $N^{\circ}$ de productos internos (sin córtex): $3^{a}$ fase de explotación & $\mathrm{BP}+\mathrm{BPF}+\mathrm{BN} 2 \mathrm{GC}+\mathrm{BN} 2 \mathrm{GE}$ \\
\hline 8 & Índice de diversidad tipométrica en los productos de talla completos ( $N^{\circ}$ de módulos de Bagolini) & $\mathrm{BP}$ \\
\hline 9 & $\begin{array}{l}\text { Índice de diversidad tipológica de útiles retocados ( } N^{\circ} \text { de morfotipos presentes según la Lista de } \\
\text { Laplace de } 1972 \text { ampliada con los morfotipos de la Prehistoria Reciente) }\end{array}$ & $B N 2 G C+B N 1 G C$ \\
\hline 10 & $\begin{array}{l}\text { Índice de diversidad de grupos tipológicos de útiles retocados ( } N^{\circ} \text { de grupos tipológicos pre- } \\
\text { sentes según la Lista de Laplace de } 1972 \text { ampliada con los grupos tipológicos de la Prehistoria } \\
\text { Reciente) }\end{array}$ & $B N 2 G C+B N 1 G C$ \\
\hline 11 & Cerámicas (variable dicotómica de presencia o ausencia en los sitios) & \\
\hline \multicolumn{3}{|c|}{$\begin{array}{l}\text { Categorías estructurales (SLA): BN1GE = Base negativa de } 1^{a} \text { generación de explotación (núcleos sobre matrices). BN2GE = Base negativa de } 2^{a} \text { generación } \\
\text { de explotación (núcleos sobre lascas). BP = Base positiva (lascas y láminas completas). BPF = Base positiva fracturada (lascas y láminas fracturadas). BN- } \\
1 \mathrm{GC}=\text { Base negativa de } 1^{\mathrm{a}} \text { generación de configuración (utensilios retocados sobre matrices). BN2GC = Base negativa de } 2^{\mathrm{a}} \text { generación de configuración } \\
\text { (utensilios retocados sobre lascas y láminas). }\end{array}$} \\
\hline
\end{tabular}

Tabla 3: Variables predictoras del Análisis Factorial Discriminante (AFD). / Predictor variables of Discriminant Function Analysis (DFA) 
calificación de «Santuario de la Prehistoria Reciente» (Apellániz y Uríbarri, 1976; Apellániz y Domingo, 1987). Otras cuevas y galerías prospectadas de la misma red con cultura material, silos, hoyos, hogares y grabados simbólicos son Cueva del Silo, Galería del Silo, Salón del Coro, Galería Baja y Galería de las Estatuas (e.g., Ortega, 2009; García et al., 2004).

Cueva Peluda: Es otro de los sectores del nivel inferior de la red de galerías. Hay huesos humanos en posición secundaria, cerámicas del Neolítico a la Edad del Bronce, restos óseos de fauna doméstica y algún artefacto pulimentado (Ortega, 2009). La geomorfología kárstica y los materiales sugieren una actividad polifuncional diacrónica de escaso impacto, relacionada con el ámbito funerario y con varias actividades complementarias esporádicas.

Cueva de El Mirador: Es otra importante cavidad del sector Sur de la sierra de Atapuerca, con una estratigrafía del Holoceno de unos $6 \mathrm{~m}$ de profundidad. La secuencia de niveles del MIR6 al MIR24 son ocupaciones continuadas del Neolítico Final al Neolítico Antiguo, con una de las dataciones sobre muestra de vida corta (Triticum dicoccum) más antiguas de la Meseta Norte: Beta-208134: 6300 \pm 50 , 5460-5080 cal BC (Vergés et al., 2016). La elevada tasa de sedimentación antrópica ha permitido individualizar en los niveles varias capas de estabulación del ganado («fumiers»), con facies grisáceas y negras formadas por la combustión periódica de excrementos, vegetales y otros restos orgánicos. En los materiales hay una amplio registro de cerámicas decoradas, industrias líticas y restos zooarqueológicos, palinológicos, carpológicos y antracológicos (e.g., Martín et al., 2009; Rodríguez et al., 2016; Vergés et al., 2016; Expósito et al., 2017).

Cueva Ciega: Es otra pequeña abertura del sector Sur de la sierra de Atapuerca. Las primeras referencias datan de 1863, con el hallazgo de restos óseos humanos de varios individuos en posición secundaria. Las prospecciones del siglo XX registraron la presencia de carbones y cerámicas del Neolítico a la Edad del Bronce (Ortega, 2009); sin embargo, no se han realizado excavaciones sistemáticas para evaluar la entidad y funcionalidad del sitio.

Túmulo de Atapuerca I: Las primeras excavaciones se ejecutaron en 1976 y 1977 tras la publicación del primer catálogo megalítico burgalés (Uríbarri, 1975). Posteriormente, se efectúan dos nuevas intervenciones en 1995 y 2001 (Palomino et al., 2006). Es un túmulo con cámara y falso corredor de orientación SE, de fundación neolítica (V-IV milenio cal BC) y con varias intrusiones calcolíticas. En el túmulo hay huesos humanos en posición secundaria y dos inhumaciones en conexión anatómica. Otros restos neolíticos son los típicos microlitos geométricos.

Túmulo del Alto de Reinoso: Es un túmulo de cámara simple con restos óseos de unas 45 personas (NMI), en posición secundaria y en conexión anatómica
(Rojo et al., 2015). En el osario hay huesos largos enmarcando cráneos, costillas formando círculos, «nidos de cráneos» y paquetes apilados de fémures y tibias. Los cráneos completos están distribuidos por la periferia de la cámara. Los análisis de isótopos de estroncio y de ADN revelan a un grupo local muy homogéneo, con fuertes lazos de parentesco. En los ajuares hay hachas pulimentadas, microlitos geométricos, cuentas de collar, punzones, espátulas, cerámicas y colmillos de jabalí. Hay tres dataciones del Neolítico sobre restos óseos humanos: MAMS-14325: 4910 \pm 25 , 3760-3640 cal BC; MAMS-14326: 4850 \pm 26 ; $3700-3540$ cal BC; MAMS-14327: 4930 $\pm 27,3770-3650$ cal BC

Túmulo de El Hundido: Es un túmulo con cámara y un corredor de piedras de mediano tamaño con orientación SE (Alonso, 2015). Según los últimos datos el enterramiento colectivo tiene un NMI de cerca de 90 personas de diferentes edades y sexos. En el osario hay inhumaciones en conexión anatómica y en posición secundaria, con recolocaciones rituales y «nidos de cráneos». La fundación del túmulo es del Neolítico considerando los microlitos geométricos, aunque las dataciones indican un uso muy intensivo durante el Calcolítico Precampaniforme. Posteriormente, se producen tres intrusiones del Calcolítico Campaniforme con tres individuos y sus respectivos ajuares.

Túmulos y menhires megalíticos prospectados: Estas estructuras están incluidas en el IACyL, y varios túmulos muestran ortostatos calizos y cráteres de hundimiento de las cámaras funerarias. Los túmulos son Atapuerca II, III y IV, Valicencia I, II y III, Villalval I, ViIlalval II, El Arenal, Asperilla, Lomas I, San Millán y Cota 1019. En el entorno próximo de los túmulos hay materiales y yacimientos del Neolítico. Otras estructuras megalíticas son los menhires de Piedrahita (Atapuerca) y Peñalada (Castrillo del Val) (e.g., Uríbarri, 1975; Ortega y Martín, 2003; Marcos, 2006, 2014).

Villafría III / Sacatierra (Villafría): Es un poblado del Neolítico que fue excavado de urgencia ante la inminente destrucción del terreno por las extracciones de áridos (Uríbarri y Martínez, 1987). Se registró un fondo de cabaña $(2.9 \times 1.8 \mathrm{~m})$ con dos hogares sobre un estrato térreo de coloración oscura que proporcionó varias cerámicas acanaladas del Neolítico Antiguo o Medio, fondos cónicos típicos del periodo, industria lítica, un anillo de hueso y restos óseos de fauna doméstica y salvaje (bóvidos, suidos y ovicápridos).

Silos funerarios del Alto de Rodilla (Monasterio de Rodilla): La extensión arqueológica del Alto de Rodilla incluye el castro de la Edad del Hierro donde se implantará la civitas Tritium Autrigonum, la necrópolis de la Edad del Hierro de Fuentesanz y varias hectáreas de terreno al Sur. En el sector SW se descubrió un «Campo de hoyos» del Neolítico a la Edad del Bronce con una excavación de $600 \mathrm{~m}^{2}$. El registro actual es de 13 estructuras negativas con restos arqueológicos: 2 estructuras rellenas de cenizas, 9 silos amortizados como 
basureros, 1 zanja y 1 silo funerario del Neolítico (CSIC1967: 6170 $\pm 55,5300-4990$ cal BC) con una inhumación en posición fetal cubierta por dos lajas y acompañada de ajuar (Alonso y Jiménez, 2015). Otro silo funerario del Neolítico a menos de $400 \mathrm{~m}$ del primero es El Hoyo (Ua-32289: 5400 $\pm 45,4350-4070$ cal BC), con un ajuar de industria lítica, conchas y anillos de hueso.

Otros yacimientos neolíticos cerca de los límites de $10 \mathrm{~km}$ de radio de Cueva Mayor son el Cerro de San Miguel (Burgos) y La Trampa (Villímar). En el Cerro de San Miguel se ha registrado con excavaciones puntuales una situación equivalente a la del Castillo de Burgos (Uríbarri et al., 1987), con un poblado del Hierro I sobre niveles de la Prehistoria Reciente. En los niveles infrapuestos y removilizados del Cerro de San Miguel hay cerámicas decoradas del Neolítico. La Trampa es un yacimiento al aire libre prospectado con cerámicas y cientos de piezas líticas, donde hay láminas retocadas y microlitos geométricos.

\section{RESULTADOS Y DISCUSIÓN}

\subsection{Resultados de las prospecciones sistemá- ticas intensivas (1999-2007)}

Las prospecciones sistemáticas intensivas de cobertura total han aportado cerca de 200 yacimientos del Pleistoceno y Holoceno en un área de estudio de 314 $\mathrm{km}^{2}$ (10 km de radio de Cueva Mayor). De los yacimientos registrados 168 tienen artefactos líticos, pulimentados y cerámicas del Neolítico, Calcolítico y Edad del Bronce. Según los análisis tecno-tipológicos y crono-culturales la gran mayoría de los 168 sitios han sido ocupados en un único periodo de la Prehistoria Reciente, siendo muy escasos los sitios ocupados en dos o tres periodos. Los 168 yacimientos más las cuevas con depósitos de la Prehistoria Reciente, las 21 estructuras megalíticas (túmulos y menhires) y los yacimientos excavados y prospectados por la Arqueología de Urgencia hacen un cómputo global en la GDB del SIG de 247 yacimientos de la Prehistoria Reciente: 231 en los $10 \mathrm{~km}$ de radio de Cueva Mayor y 16 en la periferia más inmediata (Fig. 3). La aportación de

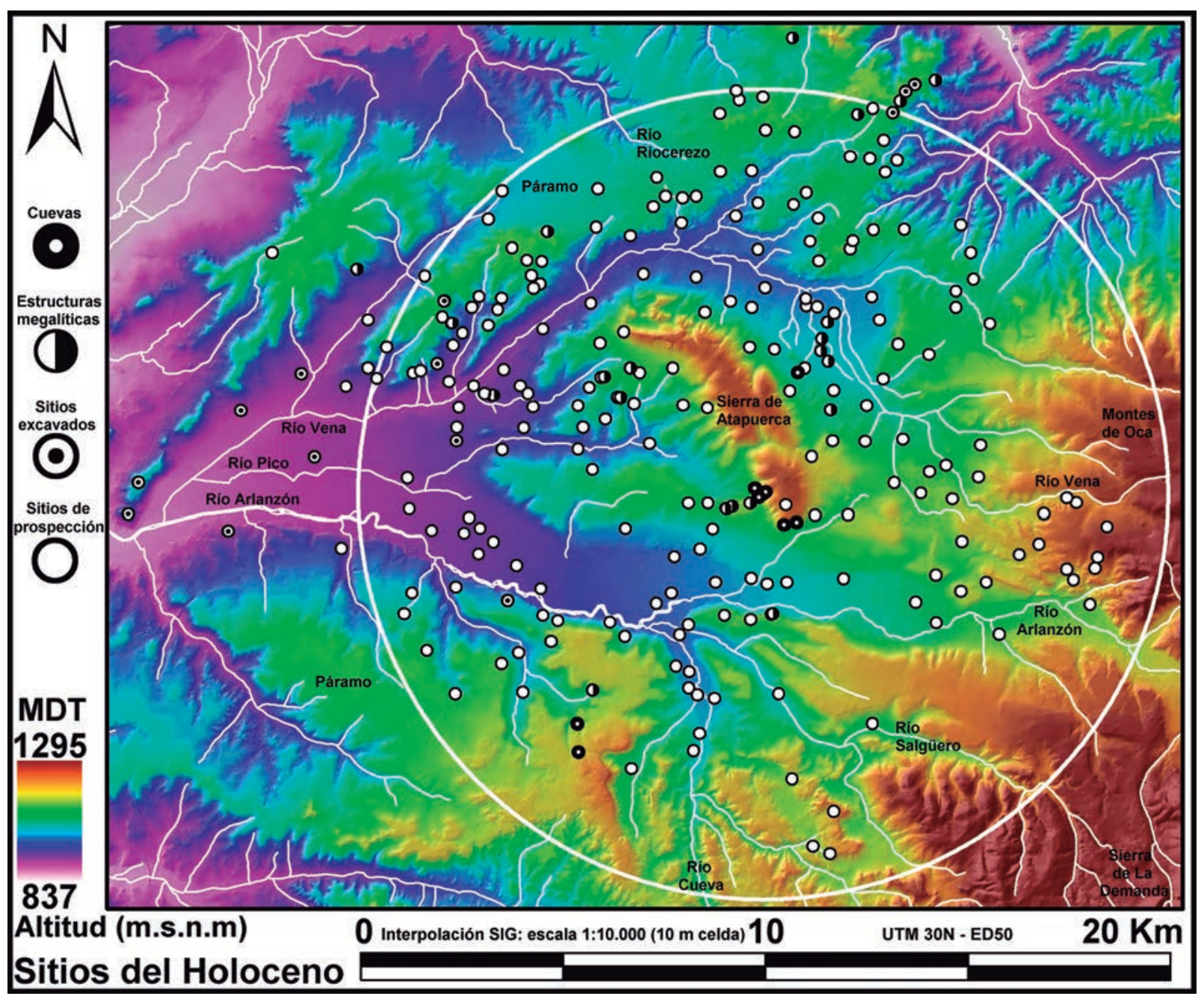

Fig. 3. MDT de altitud con los sitios de la Prehistoria Reciente (Neolítico, Calcolítico y Edad del Bronce). / Altitudinal DTM with the Late Prehistory sites (Neolithic, Chalcolithic and the Bronze Age). 
yacimientos prehistóricos del Holoceno del proyecto de investigación (1999-2007) es del 73\% de todos los sitios documentados hasta la actualidad. La densidad de sitios de la Prehistoria Reciente del área de estudio $\left(314 \mathrm{~km}^{2}\right)$ es de 0.7 sitios por $\mathrm{km}^{2}$.

\subsection{Valoración geoarqueológica}

En los aspectos geoarqueológicos subrayar la escasa alteración postdeposicional de los yacimientos de la Prehistoria Reciente; por lo general, con artefactos líticos frescos, sin rodamiento. En la tesis inédita del autor (Marcos, 2014) se implementó un análisis geoarqueológico con la interpolación de un MDT de Erosión (10 m de celda), un MDT de Pendientes (10 m de celda) y con el cálculo SIG de múltiples variables cuantitativas por cada sitio: extensión, pendiente media e índices de erosión de las dispersiones de artefactos, índices de rodamiento de los artefactos, densidad de artefactos por cada sitio, orientaciones y distancias a los cursos hídricos. El MDT de Erosión fue calculado con las técnicas del Álgebra de Mapas del ArcGIS (Raster Calculator) y según la formulación de Mitchell y Montgomery y la RUSLE (Ecuación Universal de Pérdida de Suelo), integrando en el cálculo capas digitales topográficas, geomorfométricas, hidrológicas, geológicas y medioambientales. Los análisis preliminares, pendientes de evaluación en otra publicación, demuestran la baja alteración postdeposicional de los sitios por la ausencia de correlación estadística entre las variables, con correlaciones casi nulas no significativas ( $p>0.05$ ) (Test $r$ de Pearson del SPSS).

Por el momento, y en espera de sondeos, quedan descartados los factores hídricos y erosivos en la alteración de los yacimientos. El factor principal de alteración es el laboreo agrícola mecanizado (Marcos y Díez, 2008), pero las pequeñas dispersiones de artefactos que genera son irrelevantes para el análisis territorial. Otros datos significativos son la coincidencia o superposición espacial de varias dispersiones de artefactos con varios «campos de hoyos» excavados del Neolítico a la Edad de Bronce (Marcos, 2014), y la teledetección de decenas de estructuras negativas del subsuelo (silos) con ortofotografías aéreas y con imágenes de satélite multiespectrales (combinaciones de las bandas RGB en falso color y de las bandas electromagnéticas del Infrarrojo Cercano), actualmente en proceso de análisis.

\subsection{Yacimientos del Neolítico: distribución y cultura material}

Respecto a los yacimientos del Neolítico (VI-IV milenio cal BC), la GDB del SIG es de 84 sitios: 77 sitios en los $10 \mathrm{~km}$ de radio de Cueva Mayor y 7 sitios en la periferia inmediata. La distribución de los sitios neolíticos en el MDT es la siguiente: 5 cuevas con galerías intrakársticas, 16 túmulos megalíticos funerarios, 2 men- hires, 2 silos funerarios al aire libre y 59 asentamientos al aire libre prospectados y/o excavados (Fig. 4).

Los sitios prospectados del Neolítico manifiestan un tecnocomplejo de microlascas y laminillas con alta representación de la producción laminar en los núcleos (piramidales, prismáticos, cónicos y ortogonales de láminas), productos de talla y útiles retocados. Los sitios muestran la típica estructura tipológica del Neolítico, con abundancia de láminas simples con huellas de uso, láminas de hoz simples con lustre de cereal, láminas y lascas con muescas y denticulados, raspadores sobre láminas y lascas, microlitos geométricos con retoques abruptos y en doble bisel (segmentos, trapecios y triángulos), láminas de retoque continuo marginal, perforadores sobre láminas y lascas, taladros largos sobre láminas, láminas de dorso, láminas truncadas, láminas de dorso truncadas, buriles, puntas foliáceas primitivas con retoques planos, continuos, marginales y unifaciales, útiles pulimentados (hachas, azuelas y cinceles), etc. También son muy abundantes las láminas fracturadas de forma intencional mediante la técnica de flexión simple. La técnica del microburil es muy rara. Asimismo, el tratamiento térmico para la producción de láminas de buena calidad está presente en muchas piezas (v. Marcos, 2014).

En las cerámicas neolíticas hay varias tipologías de formas con bases convexas y decoraciones muy semejantes a las de los niveles de Cueva Mayor y Cueva de El Mirador, con recipientes globulares y hemiesféricos con bandas paralelas de boquiques inciso-impresos y pseudoboquiques impresos, acanalados horizontales, mixtos de motivos inciso-impresos y acanalados, impresiones de matrices, líneas incisas paralelas y verticales, cordones simples, asas verticales y horizontales, perforaciones, pastillas repujadas, etc. (Ibid., 2014).

\subsection{Clasificación funcional de los sitios neolíti- cos y distribución territorial}

El AFD fue ejecutado con todos los yacimientos de la Prehistoria Reciente de las prospecciones sistemáticas $(N=168)$ para aplicar el mismo método y poder incluir una muestra muy significativa estadísticamente. El AFD genera en el análisis una segunda variable categórica en la matriz de sitios y variables, asignando a cada sitio a un grupo funcional según la clasificación automática del modelo predictivo de las dos funciones discriminantes (Tabla 4). Posteriormente, el SPSS ejecuta una validación cruzada entre las dos clasificaciones, calculando el porcentaje de concordancia.

El porcentaje de concordancia es del 84\%, siendo, por tanto, un porcentaje muy significativo para aceptar la clasificación funcional propuesta con criterios objetivos. También son muy significativos los test Lambda de Wilks $(p<0.001)$ y $M$ de Box $(p<0.001)$ del SPPS para contrastar la robustez del AFD. Otro dato muy significativo es que la primera función discriminante explica el 


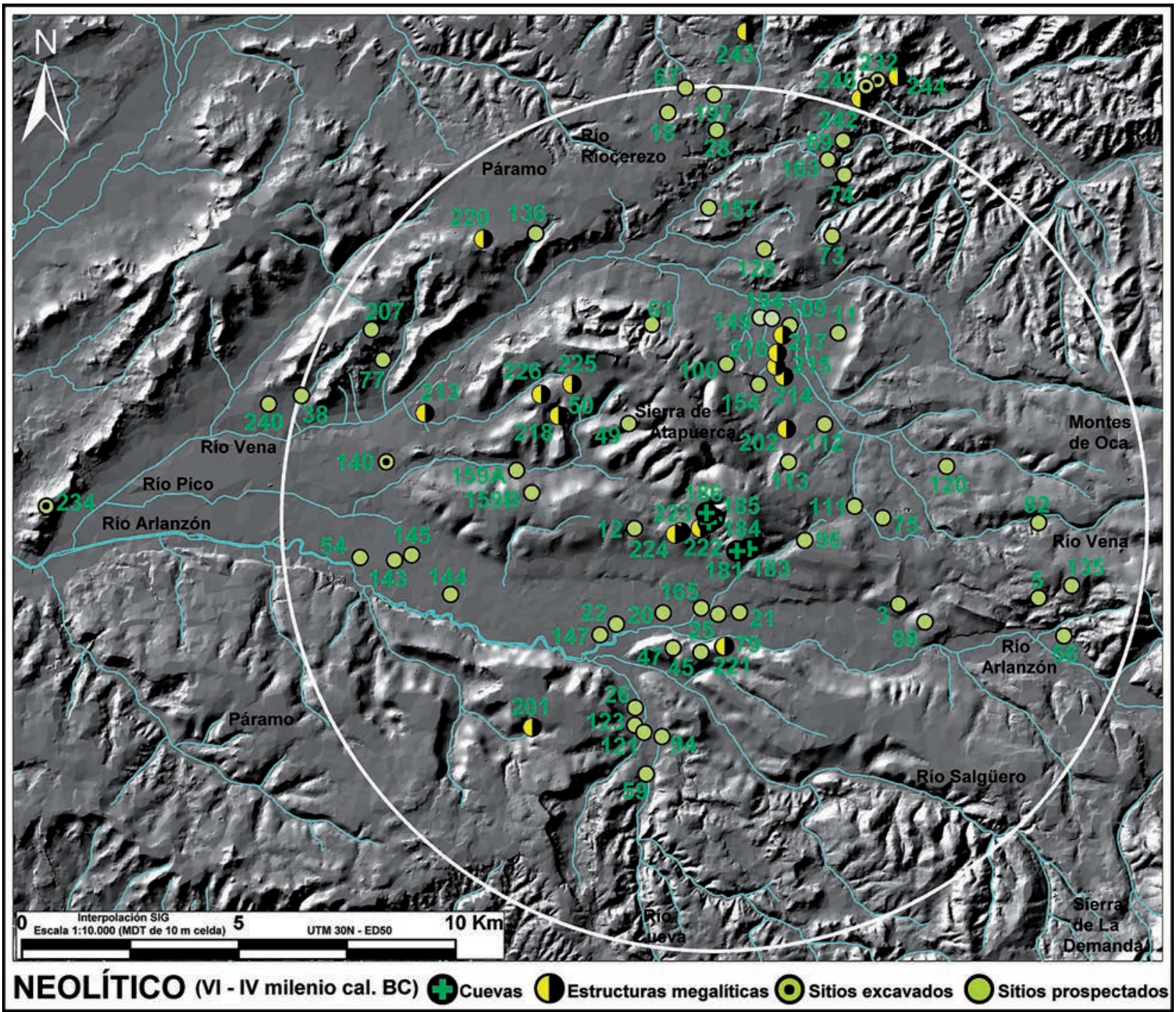

Fig. 4. MDT con los sitios del Neolítico (códigos): 3. Alto La Rasa. 5. Arretur. 11. Barranquillo. 12. Bermejuela. 18. $C^{\circ}$ las Coloradas. 20. $C^{\circ}$ del Chorrón. 21. $\mathrm{C}^{\circ}$ del Molino. 22. $C^{\circ}$ de lbeas de Juarros. 25. $C^{\circ}$ Real. 26. $C^{\circ}$ Renedo. 28. Canal de Castañas. 38. Carriberó. 45. Cuesta del Hoyo. 47. Dehesa del Canto. 49. Derechos de Valdemuñón. 50. El Arenal. 54. El Millar. 56. El Navesario. 59. El Velar. 61. Entremesada. 67. Fuente Redonda. 69. Guindaleras. 73. Irias Darte. 74. Junto a la Iglesia. 75. La Barraca A (1C). 77. La Cárcava. 79. La Charca. 82. La Huerta. 94. Las Claves. 96. Las Coloradas II. 98. Las Eras. 100. Las Presas. 109. Los Haciales. 111. Los Pedernales. 112. Manzanares. 113. Marigarcía-Cdo. de Agés. 120. Ontecillas. 121. Pasadilla. 123. Peñuelo. 128. Pradillos. 135. Quintana II. 136. Rasgalbarcas. 140. Sacatierra-Villafría III. 143. San Medel II. 144. San Medel III. 145. San Medel IV. 147. San Millán I. 149. Santillana. 154. Tras La Fuente. 157. Trascastro. 159(A). Valdefrades A. 159(B). Valdefrades B. 163. Vallejuelo. 165. Vega Sextil. 181. Cueva Ciega. 183. Cueva de El Mirador. 184. Cueva del Silo. 185. Cueva Mayor. 186. Cueva Peluda. 194. Los Humedales. 197. Las Coloradas III. 201. Menhir de Peñalada. 202. Menhir de Piedrahita. 207. Páramo Rebollo II. 213. Asperilla. 214. Atapuerca I. 215. Atapuerca II. 216. Atapuerca III. 217. Atapuerca IV. 218. El Arenal. 220. Lomas I. 221. San Millán. 222. Valicencia I. 223. Valicencia II. 224. Valicencia III. 225. Villalval I. 226. Villalval II. 232. Alto de Rodilla (silo funerario). 234. Cerro de San Miguel. 240. La Trampa. 242. Alto de Reinoso. 243. Cota 1019. 244. El Hundido. 246. El Hoyo (silo funerario). / DTM with the Neolithic sites (codes).

\begin{tabular}{|c|c|c|c|c|c|c|c|c|c|c|c|c|}
\hline 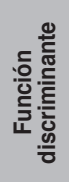 & 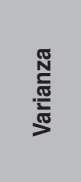 & 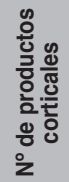 & 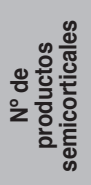 & 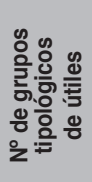 & 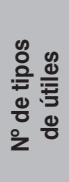 & 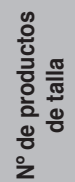 & 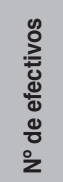 & 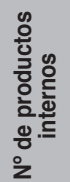 & 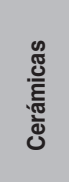 & 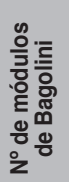 & 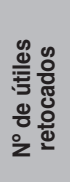 & 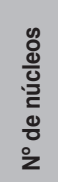 \\
\hline 1 & $89.1 \%$ & .618 & .535 & .046 & .075 & .462 & .369 & .309 & -.060 & .101 & .188 & .176 \\
\hline 2 & $10.9 \%$ & .384 & .477 & .718 & .655 & .581 & .574 & .573 & .556 & .547 & .513 & .405 \\
\hline
\end{tabular}

Tabla 4: Matriz de correlaciones con los coeficientes entre las variables independientes discriminantes (predictoras) y las dos funciones discriminantes / Correlation matrix showing the coefficients between discriminant independent variables (predictors) and the two discriminant functions. 
89.1\% de la varianza. El taller de sílex neógeno Los Pedernales (111) ha sido pronosticado como el sitio más atípico, quedando aislado en los gráficos factoriales (Fig. 5: A y B). Asimismo, hay dos sitios complementarios atípicos, sobre afloramientos de sílex neógeno, que fueron clasificados por sus materiales como talleres de sílex de menor entidad. Por último, destacar la graduación funcional, proyectándose en la parte superior de los gráficos los poblados de mayor entidad, -mayor duración y/o intensidad de la ocupación-, y en la inferior, con valores negativos, los sitios complementarios con actividades económicas efímeras o puntuales.

Después de la validación robusta de la clasificación funcional, los 59 yacimientos al aire libre del Neolítico presentan la siguiente distribución: 39 poblados (estables y/o estacionales), 17 sitios complementarios (recurrentes y/o efímeros) y 3 talleres de sílex neógeno sobre afloramientos de sílex. El MDT proyecta la distribución territorial de los 84 sitios del Neolítico con la simbología funcional, con un símbolo propio para las 5 cuevas, 16 túmulos funerarios megalíticos, 2 menhires y 2 silos funerarios al aire libre (Fig. 6).

Los poblados, sensu lato o espacios habitacionales, son los sitios que jerarquizan el territorio. La mayor diversidad de actividades económicas ha generado en el registro arqueológico una mayor complejidad tecnológica y tipológica, con una mayor cantidad y diversidad de artefactos líticos y cerámicos. Las cadenas operativas de producción lítica de las materias primas autóctonas suelen estar completas y equilibradas, con presencia de núcleos (BN1GE y BN2GE), productos de talla (BP y BPF) y productos retocados (BN2GC y BN1GC) con mayor variabilidad morfotécnica y morfofuncional. Es decir, hay una mayor diversidad de núcleos de lascas y láminas (piramidales, prismáticos, cónicos, ortogonales, discoides, etc.), unas técnicas de talla más predeterminadas y elaboradas, -a veces con tratamiento térmico laminar-, una mayor diversidad tipométrica y una mayor variedad de útiles retocados representativos de las diferentes actividades domésticas: p.e., talla lítica, producción de utensilios, manufacturas, producción agrícola y ganadera, procesado de productos bióticos secundarios y consumo familiar.

Por el contrario, en los sitios complementarios no es posible inferir con el registro arqueológico de superficie la diversidad de actividades socioeconómicas de los poblados, sugiriendo que son sitios satélites de la movilidad logística y residencial: p.e., zonas de caza, pesca y recolección, zonas de recolección agrícola, zonas de estabulación ganadera, altos de la movilidad pecuaria trasterminante y campamentos temporales. La menor diversidad de actividades económicas o una actividad más especializada ha generado en el registro arqueológico una menor diversidad tecnológica, tipológica y de materias primas. Las cadenas de producción lítica suelen estar incompletas y desequilibradas, con escasa variedad morfotécnica y morfofuncional. Las cerámicas no son representativas de un menaje doméstico con diversidad de formas, tamaños y grosores. También es recurrente la ausencia de molinos y manchones oscuros de posibles estructuras negativas del subsuelo.

Por último, los talleres de sílex neógeno muestran grandes nódulos de sílex naturales, una cadena de producción lítica completa y desequilibrada por la escasa presencia y baja diversidad de utensilios retocados, una alta cantidad y densidad de piezas, una alta proporción de productos de talla con gran diversidad tipométrica (micro y macro), una amplia variedad de núcleos con predominio de las estrategias de talla poco predeterminadas e informes, y una alta proporción de productos de talla corticales y semicorticales de las primeras fases de la explotación lítica.

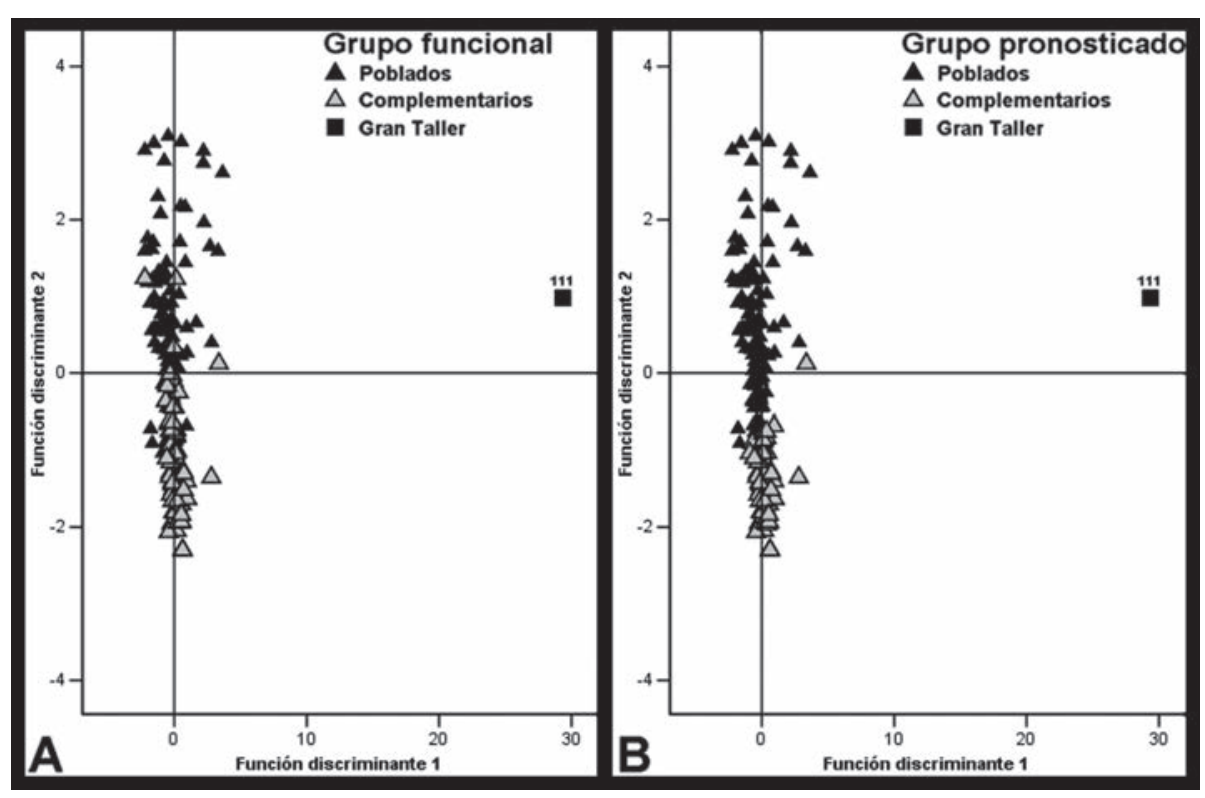

Fig. 5. Gráficos del Análisis Factorial Discriminante (AFD). A. Clasificación funcional. B. Clasificación del modelo predictivo. / Factorial plots of the Discriminant Function Analysis. A. Functional classification. B. Predictive model classification. 


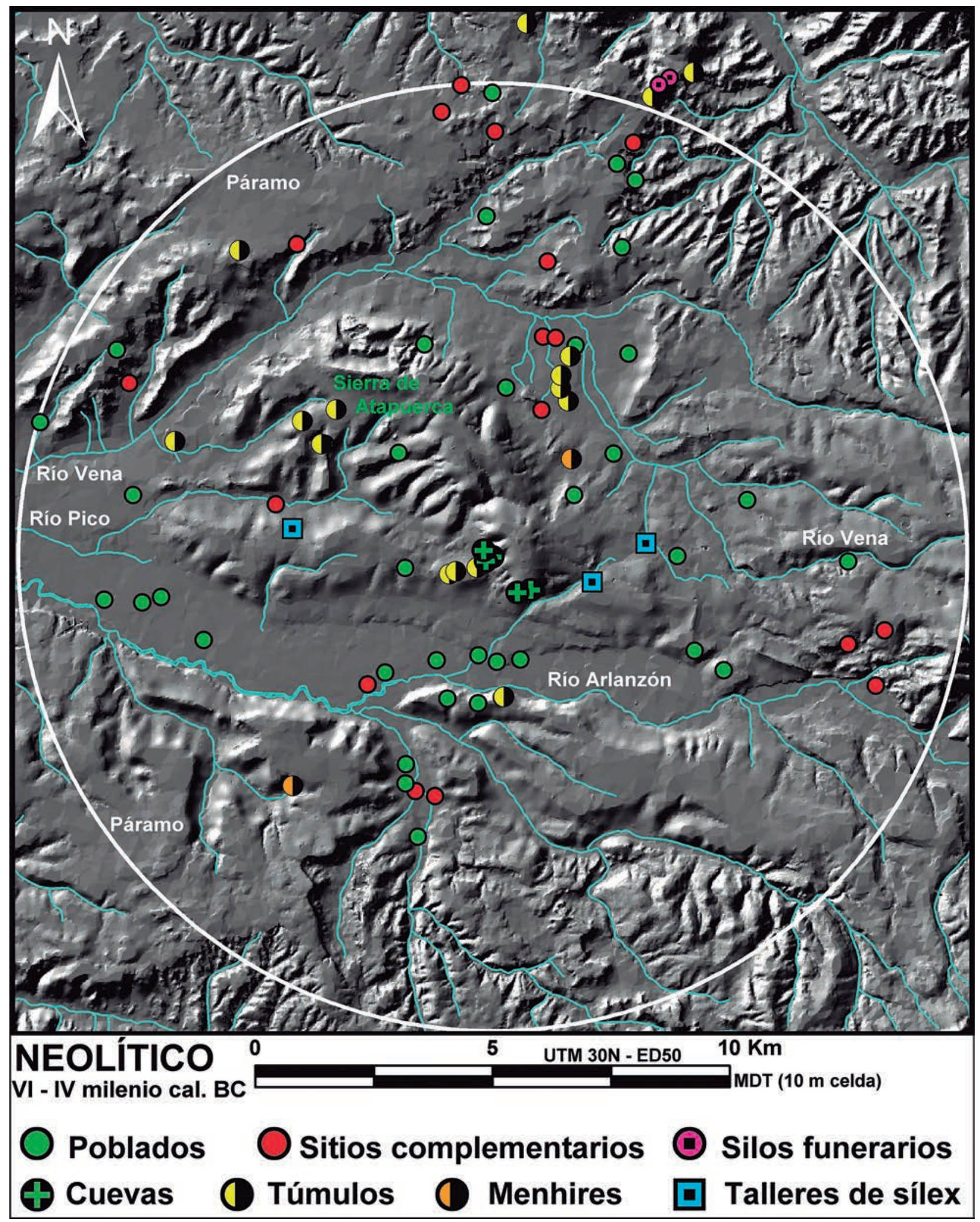

Fig. 6. MDT con la distribución espacial y la organización funcional del Neolítico (VI-IV milenio cal BC). Los test geoestadísticos del SIG han sido aplicados sobre el área de prospección sistemática (10 km de radio de Cueva Mayor: círculo blanco). / DTM with the Neolithic spatial distribution and functional organization (VI-IV millennium cal BC). The GIS geostatistical test have been applied in the systematic survey area (10 km radius of Mayor Cave: white circle). 


\subsection{Análisis espacial y organización funcional del poblamiento neolítico}

\subsubsection{Test geoestadísticos de distribución espa- cial: la distribución territorial diacrónica}

Los test de distribución espacial calculados sobre el área circular de prospección sistemática de 314 km² ( v. MDT. Fig. 6) muestran un patrón de distribución concentrado: Average Nearest Neighbor Test y Multi-Distance Spatial Cluster Analysis: Ripley's K-function. Los valores de la distribución global de todos los sitios del Neolítico son: ANN ratio $=0.77, Z$ Score $=-3.39$ s.d., $p<0.01$. Los resultados del test del vecino más próximo son muy robustos, indicando una probabilidad menor del $1 \%$ de que este patrón concentrado sea el resultado de procesos aleatorios. La K de Ripley, -el test inferencial de mayor precisión multiescalar y con fórmula de corrección del efecto borde-, también demuestra con 99 permutaciones aleatorias (método Monte Carlo) que hay un patrón de distribución concentrado de sitios $(p<0.01)$ para la mayoría de los 10 intervalos de distancias por rangos de $1000 \mathrm{~m}$, con una curva de valores observados siempre por encima de los esperados hasta el rango de $8000 \mathrm{~m}$ de cada sitio (Fig. 7: A y B)
Para contrastar el patrón de distribución de los sitios habitacionales que jerarquizan el territorio el análisis fue repetido sólo con los poblados y las cuevas habitacionales, con los siguientes valores: ANN ratio $=$ 0.86 , Z Score $=-1.71$ s.d., $p<0.1$. En este caso el patrón de distribución habitacional a macroescala también es concentrado, al igual que demuestra la función $\mathrm{K}$ de Ripley $(p<0.01)$, la cual indica de nuevo con 99 permutaciones aleatorias que hay un patrón concentrado de sitios multiescalar hasta el rango de $8000 \mathrm{~m}$ de cada sitio (Fig. 7: C y D). En conclusión, la distribución espacial diacrónica del Neolítico es muy representativa del interés por habitar y explotar determinados espacios de forma recurrente.

Para analizar las concentraciones de sitios y las zonas recurrentes de mayor actividad económica del territorio se han realizado dos análisis de densidad de sitios por km² (Kernel Density Analysis): «Densidad global» (poblados, cuevas y sitios complementarios) (Fig. 8) y «Densidad habitacional» (poblados y cuevas habitacionales) (Fig. 9). Las estructuras megalíticas fueron excluidas del análisis para contrastar sólo las zonas de mayor explotación económica. En el cálculo se aplicó el algoritmo con un radio de búsqueda de $2 \mathrm{~km}$ de cada sitio, siendo el parámetro más óptimo según las prue-

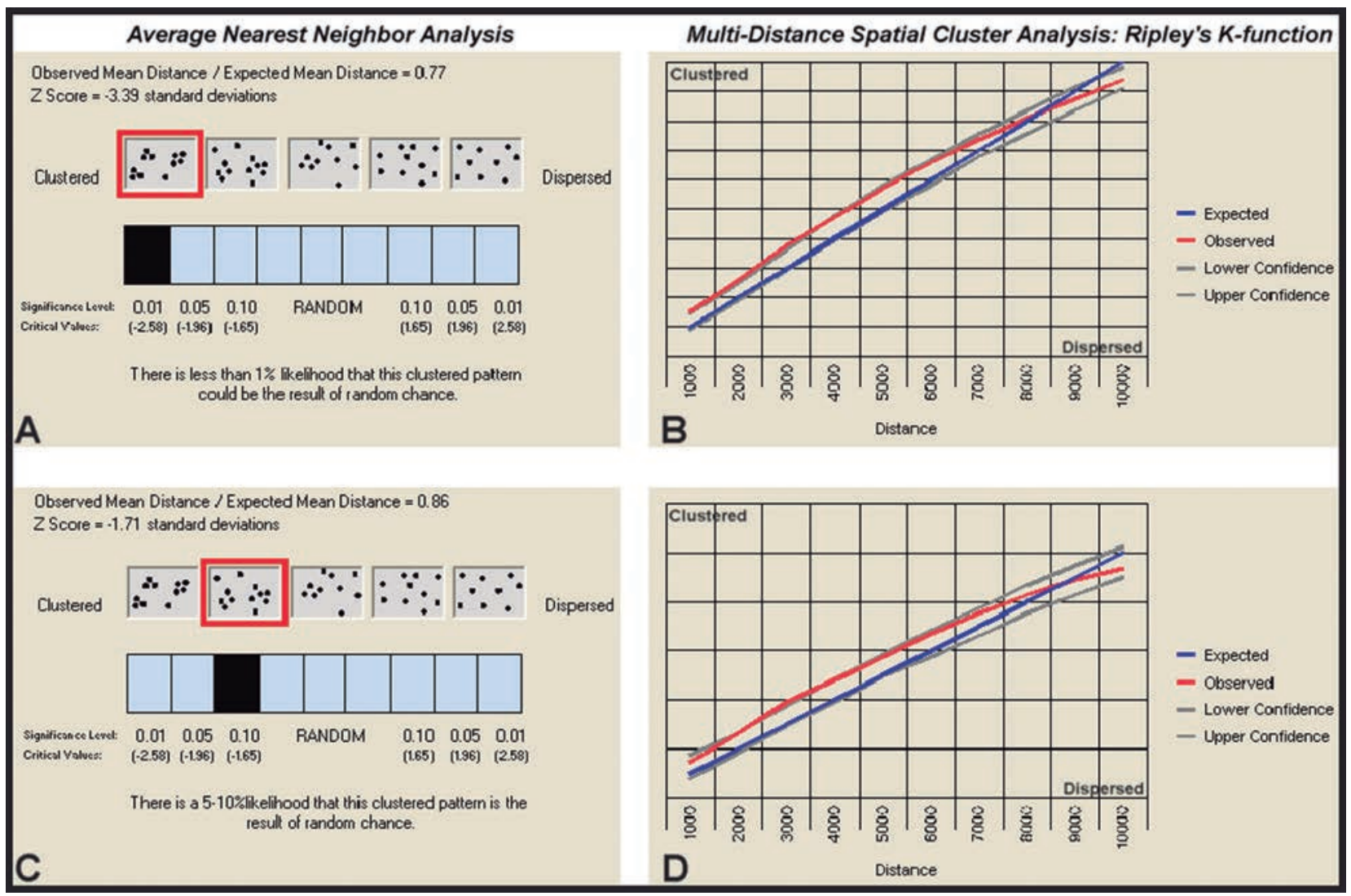

Fig. 7. Resultados geoestadísticos del patrón distribucional del Neolítico (10 km de radio de Cueva Mayor). A y B: Test del Análisis Global (poblados, cuevas y sitios complementarios). C y D: Test del Análisis Habitacional (poblados y cuevas habitacionales). / Geostatistical results of the Neolithic distributional pattern (10 km radius of Mayor Cave). A and B: Test of the Global Analysis (settlements, caves and complementary sites). C and D: Test of the Analysis of Inhabitation Zones (settlements and housing caves). 


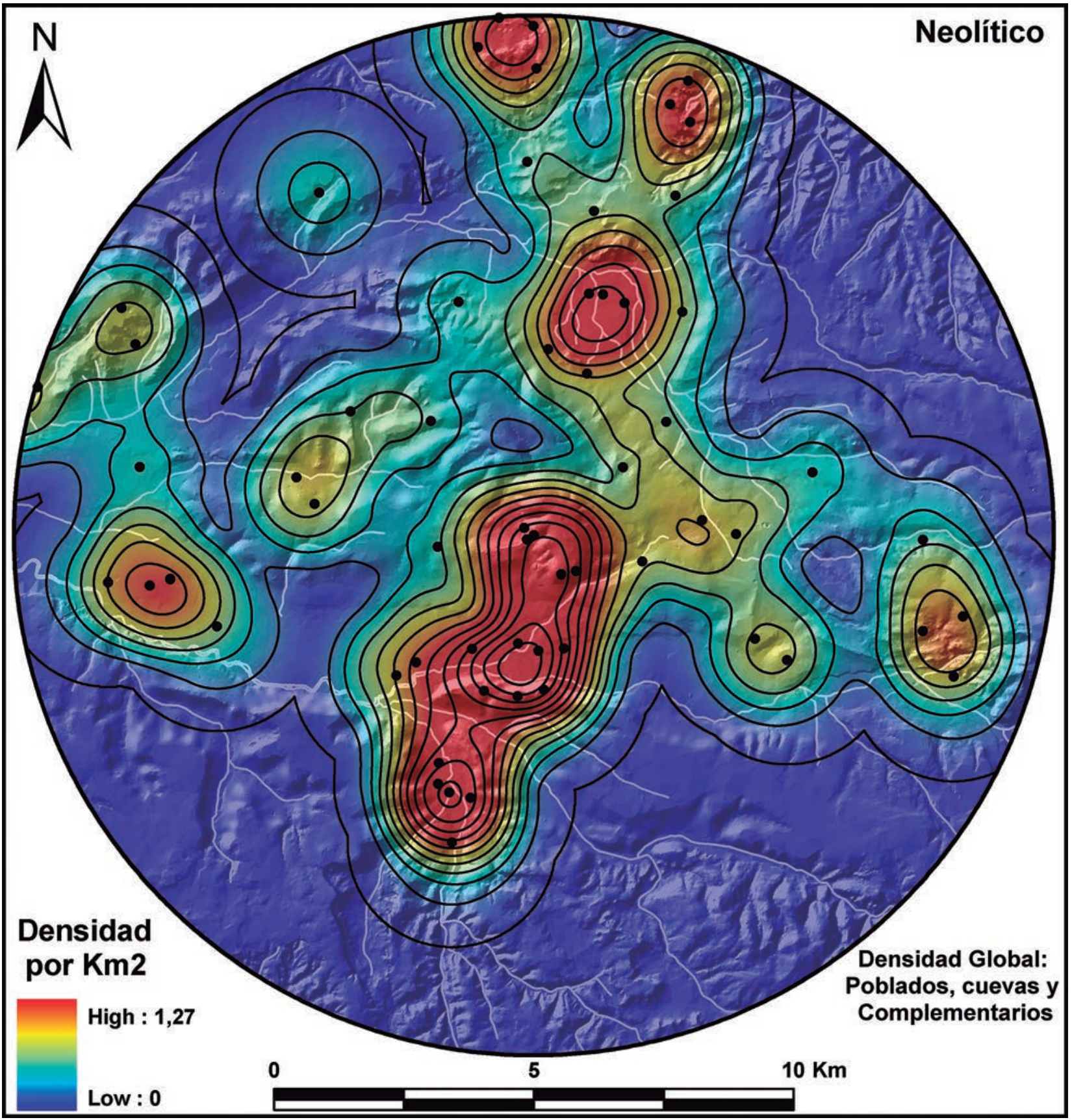

Fig. 8. MDT con la Densidad Global de sitios del Neolítico (VI-IV milenio cal BC) en el área de prospección sistemática (10 km de radio de Cueva Mayor): Kernel Density Analysis de poblados, cuevas y sitios complementarios. / DTM with the Global Density of the Neolithic sites (VI-IV millennium cal BC) in the systematic survey area (10 km radius of Mayor Cave): Kernel Density Analysis of settlements, caves and complementary sites.

bas de ensayo realizadas y los test geoestadísticos resultantes. La correlación estadística ( $r$ de Pearson) entre los dos ráster cuantitativos de densidad del Neolítico es muy alta y positiva: $r=0.86(p<0.01)$. De este índice se infiere que hay una correlación espacial robusta entre las zonas de mayor actividad socioeconómica con las zonas de mayor densidad habitacional, con un alto grado de coincidencia, siendo los dos análisis concluyentes para determinar las zonas de mayor explotación económica e interacción social del territorio.
Para contrastar las concentraciones de sitios estadísticamente significativas se han aplicado otras técnicas geoespaciales del SIG. Primero, con la superposición de los puntos vectoriales de los sitios a los mapas ráster de densidad se ha extraído el valor cuantitativo de la celda ráster que ocupa cada sitio para hacer un análisis doble (Spatial Analyst Tools): valor de los puntos vectoriales de los sitios de la «Densidad global» y valor de los puntos vectoriales de los sitios de la «Densidad habitacional». Con los valores tabulados en 


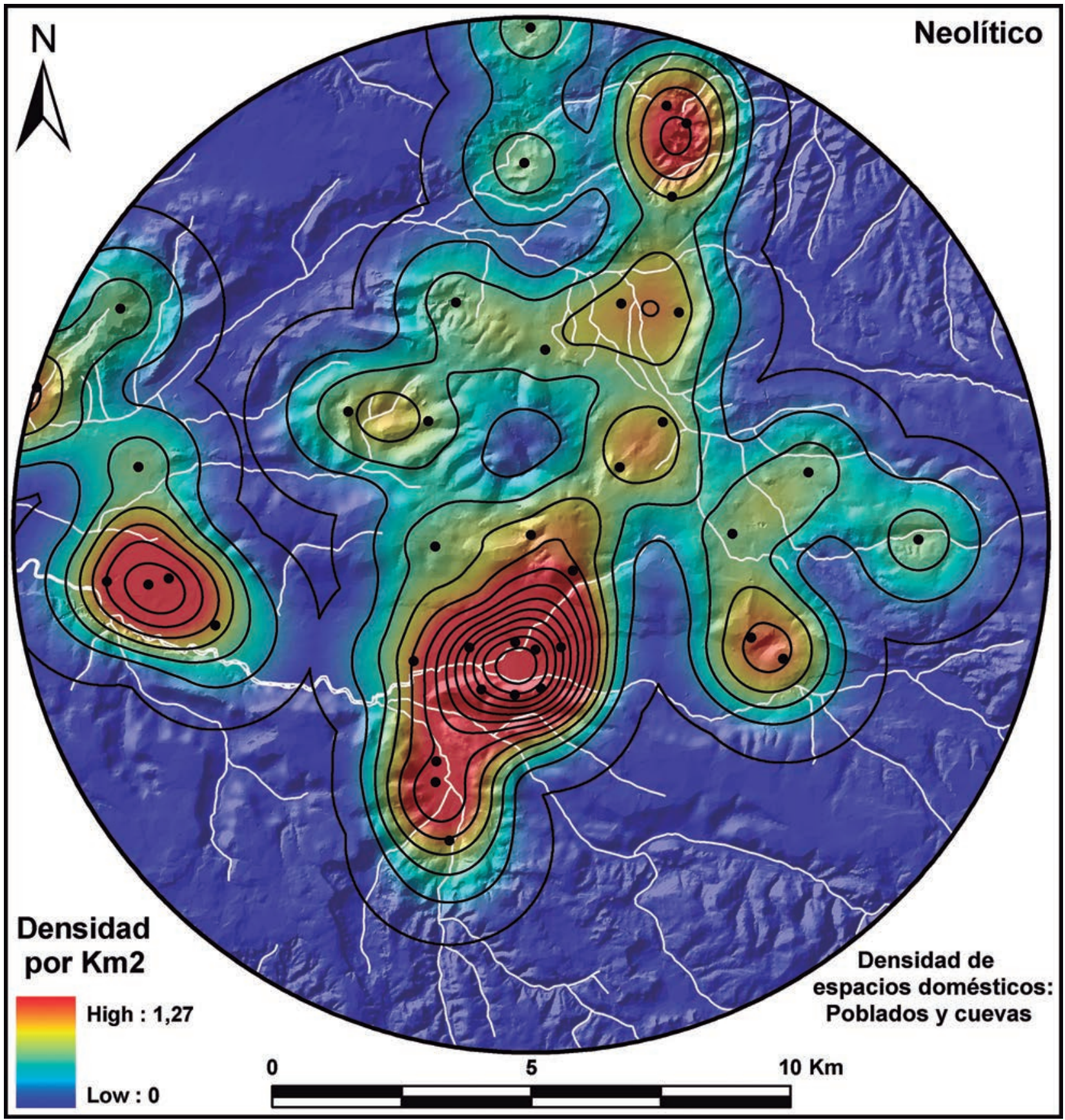

Fig. 9. MDT con la Densidad Habitacional de sitios del Neolítico (VI-IV milenio cal BC) en el área de prospección sistemática (10 km de radio de Cueva Mayor): Kernel Density Analysis de poblados y cuevas habitacionales. / DTM with the Density of Inhabitation Zones of the Neolithic sites (VI-IV millennium cal BC) in the systematic survey area (10 km radius of Mayor Cave): Kernel Density Analysis of settlements and housing caves.

las GDBs de los sitios se han ejecutado otros tres test geoestadísticos (Spatial Statistics Tools), cuyo cálculo depende de la ubicación espacial de los sitios y del valor cuantitativo de la variable: Spatial Autocorrelation (I de Moran), High/Low Clustering (G general de Getis-Ord) y Hot Spot Analysis (Gi* de Getis-Ord) (Fig. 10).

La I de Moran mide la autocorrelación espacial de los sitios en función de sus coordenadas $(X / Y)$ y de la variable cuantitativa tabulada, contrastando si el pa- trón es concentrado, aleatorio o disperso. En los dos análisis realizados (global y habitacional) hay una autocorrelación espacial positiva estadísticamente significativa $(p<0.01)$, la cual se produce cuando los valores altos de los puntos se agrupan con otros valores altos y los valores bajos con otros bajos; es decir, un patrón distribucional de la variable altamente agrupado. Los valores de probabilidad del test $\mathrm{G}$ general de Getis-Ord (High/Low Clustering) también son muy significativos 


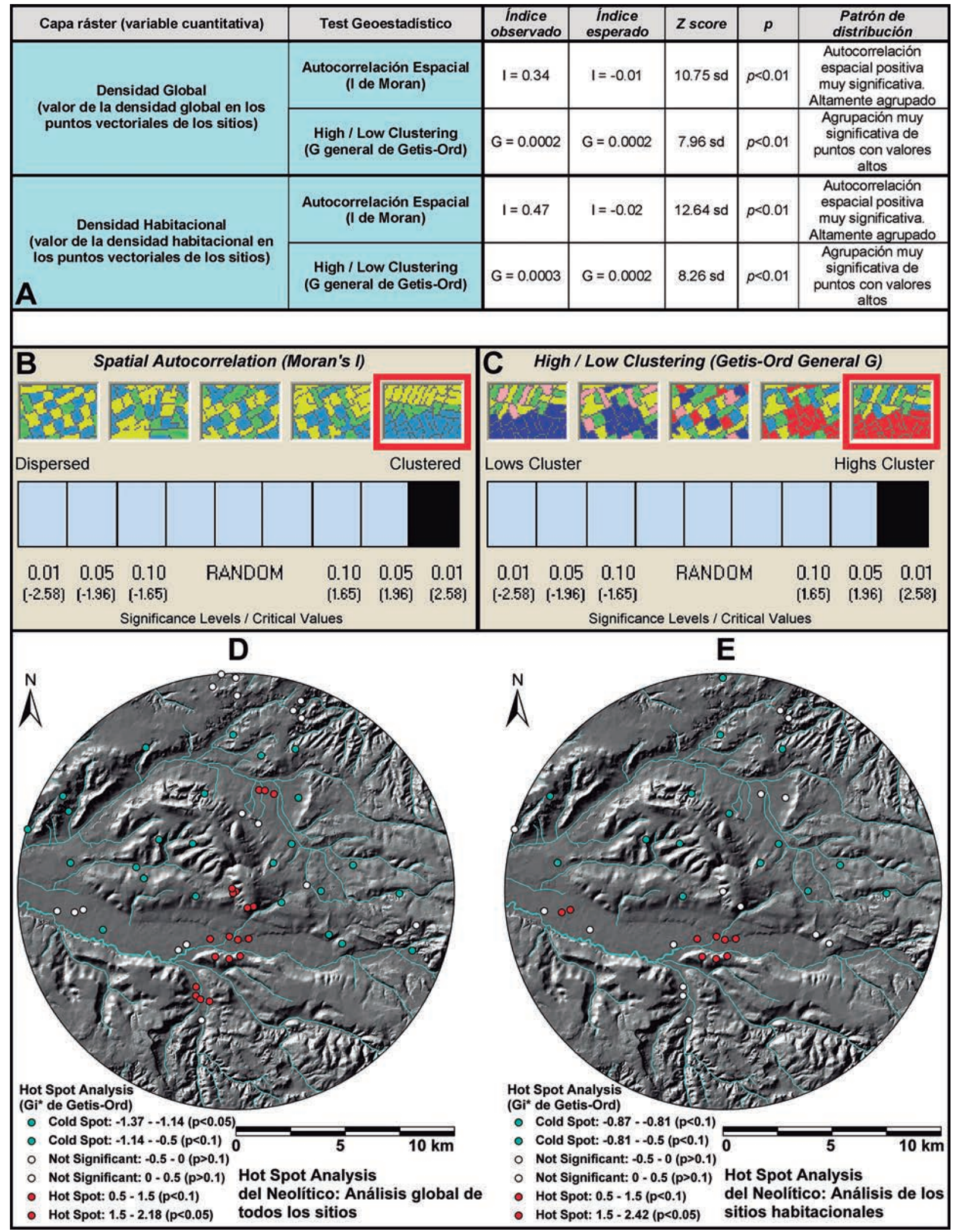

Fig. 10. Técnicas del Análisis Espacial del SIG aplicadas a los sitios del Neolítico para contrastar concentraciones estadísticamente significativas en el Análisis Global y Análisis Habitacional. A, B y C: Test I de Moran (Spatial Autocorrelation) y Test G general de Getis-Ord (High/Low Clustering). D y E: Test Gi* de Getis-Ord (Hot Spot Analysis) sobre los MDTs de sombra topográfica. / GIS spatial analysis techniques applied to the Neolithic sites to verify statistically significant concentrations in the Global Analysis and Analysis of Inhabitation Zones. A, B and C: Moran's I Test (Spatial Autocorrelation) and Getis-Ord general G Test (High/Low Clustering). D y E: Getis-Ord Gi* Test (Hot Spot Analysis) on the topographic shadow DTMs. 
$(\mathrm{p}<0.01)$ en los dos análisis (global y habitacional), confirmando los resultados del primer test pero matizando estadísticamente que no hay concentraciones significativas de sitios con valores bajos, sino con valores altos.

Precisamente, el test Gi* de Getis-Ord (Hot Spot Analysis) nos proyecta sobre los MDTs del relieve los puntos vectoriales de los sitios implicados en la concentración del poblamiento más significativa del territorio, tanto en el análisis global como en el análisis habitacional. La técnica discrimina los puntos según el rango de valores de la $\mathrm{Gi}^{\star}$ observada, las puntuaciones $Z$ y los intervalos de confianza o niveles de significación. Los puntos no significativos ( $p>0.1)$, -puntos en blanco con puntuaciones $Z$ cercanas a $0-$, son los sitios cuyos valores de densidad no difieren de la media de la densidad del territorio: 0.2 sitios por $\mathrm{km}^{2}(\sigma=0.23)$ en el análisis global y 0.12 sitios por $\mathrm{km}^{2}(\sigma=0.17)$ en el análisis habitacional. Los puntos "fríos" (cold spots), -puntos azules con puntuaciones $Z$ negativas-, son los sitios con valores estadísticamente significativos $(p<0.1$ y $\mathrm{p}<0.05)$ muy por debajo de la media de la densidad del territorio. Y, los puntos "calientes" (hot spots), -puntos rojos con puntuaciones $Z$ positivas-, son los sitios con valores estadísticamente significativos $(p<0.1$ y $\mathrm{p}<0.05)$ muy por encima de la media de la densidad del territorio, aproximándose en varios casos, con puntuaciones Z positivas cercanas a 3, al valor de $p<0.01$.

En definitiva, los puntos "calientes" del test $\mathrm{Gi}^{*}$ de Getis-Ord proyectados en los MDTs demuestran que la concentración de sitios más significativa estadísticamente se localiza en el sur de la sierra de Atapuerca y la confluencia del río Cueva con el Arlanzón, con una asociación espacial de cuevas, poblados, talleres de sílex, túmulos y otros sitios complementarios. Los test geoestadísticos indican, además, que aunque en los mapas ráster de densidad hay varios complejos de sitios, -o varios focos de alta densidad (multifocal)-, hay una gran estructura espacial de poblamiento altamente agrupada de tendencia unifocal al sur y al este de la sierra de Atapuerca que conecta los complejos más importantes. Esta estructura espacial de orientación NE-SW se relaciona con las principales rutas de la movilidad logística y residencial, y con las zonas de mayor explotación económica e interacción social de las comunidades neolíticas.

\subsubsection{Discusión del Análisis Espacial}

La densidad y la diversidad funcional de los sitios neolíticos que rodean la sierra de Atapuerca demuestra que los potentes depósitos arqueoestratigráficos de las cuevas son el resultado de una intensa ocupación, gestión y explotación económica del territorio circundante. Desde esta perspectiva, las cuevas no son los núcleos básicos para la neolitización del territorio, sino sólo el efecto de las reiteradas visitas de los grupos asentados en los valles que las articulan, jerarquizan e incorporan al territorio tribal como espacios polifuncionales: esta- bulación del ganado, zonas de hábitat, explotación del sílex cretácico, lugares simbólicos o santuarios y espacios funerarios.

En consecuencia, el análisis espacial es concluyente para comprender la potencia sedimentaria de los niveles neolíticos de estabulación de Cueva Mayor y Cueva de El Mirador (>2-3 m de espesor), la estacionalidad inferida de los patrones de edad del ganado dominante (Ovis aries y Capra hircus) y la diversidad de restos carpológicos registrados de varios biotopos (Martín et al., 2009; Rodríguez et al., 2016; Vergés et al., 2016; Expósito et al., 2017), porque en su entorno inmediato hay una concentración de sitios estadísticamente significativa («zona caliente») donde resulta muy probable la movilidad logística y estacional de los ovicápridos entre los poblados del valle y las cuevas de la sierra entre el VI y el IV milenio cal BC.

En los MDTs del Neolítico podemos apreciar la ubicación de las cuevas de la sierra de Atapuerca: Cueva Mayor, Cueva Peluda, Cueva del Silo, Cueva Ciega y Cueva de El Mirador. En la red intrakárstica destacan los espacios con actividad simbólica y funeraria de la Galería del Sílex y la Galería del Silo. En las inmediaciones también figura la concentración de túmulos de Valicencia I, II y III. Otra concentración de túmulos asociados al humedal de Atapuerca (mollisoles) figura al este de la sierra en el fondo del valle del río Vena: túmulos de Atapuerca I, II, III y IV. Al oeste de la sierra aparece la concentración de túmulos de Villalval I, II y El Arenal. Otra zona de interés es el NE del MDT, -límite de las cuencas del Duero y Ebro-, con la asociación espacial de los túmulos del Alto de Reinoso, El Hundido y los silos funerarios del Alto de Rodilla y El Hoyo. Las restantes estructuras megalíticas se dispersan por diferentes biotopos y ecotonos.

Un dato muy significativo del entorno de la sierra de Atapuerca es la asociación espacial de varios poblados y sitios complementarios con las necrópolis tumulares y con los silos de inhumación. En algunos de estos poblados se registraron cerámicas decoradas con bandas paralelas de pseudoboquiques impresos del Neolítico Antiguo (Marcos, 2014), muy similares a las de la Cueva de El Mirador y del Alto Ebro (e.g., Vergés et al., 2016; Alday et al., 2009), demostrando que las zonas iniciales de la neolitización del último tercio del VI milenio cal BC, -p.e., el sur de la sierra de Atapuerca y la zona de los humedales del valle del Vena-, son reocupadas en el Neolítico Medio y Final.

Otras zonas interesantes son la ubicación de los talleres de sílex neógeno al este y al oeste de la sierra de Atapuerca (Los Pedernales, Las Coloradas y Valdefrades), con importantes afloramientos de sílex neógeno con bloques de tamaño métrico, al igual que en las superficies terciarias miocenas de la plataforma elevada de los túmulos de Villalval I, II y El Arenal.

Los restos materiales de los poblados indican que sólo estuvieron ocupados por una familia nuclear 
o unas pocas familias cada uno (familia extensa). Los materiales constructivos de las cabañas serían muy efímeros (barro, postes de madera y fibras vegetales), ya que sólo hay registro de silos, hoyos, fondos de cabaña y hogares en los sitios neolíticos excavados (e.g., Villafría III / Sacatierra, Los Cascajos / El Blanquillo, Alto de Rodilla, El Hoyo, Fuente Celada, Molino de Arriba, Los Prados). La clasificación funcional multivariante de los sitios prospectados indica una graduación de los poblados y sitios complementarios, sugiriendo que hay poblados estables y estacionales, zonas de caza y recolección, zonas de producción agrícola, zonas de estabulación ganadera y altos de la movilidad pecuaria trasterminante de corto alcance.

Estamos, por tanto, ante un poblamiento neolítico donde las familias nucleares se dispersan por el paisaje con pequeñas explotaciones agropecuarias, las cuales se concentran, a su vez, en varios complejos de sitios representativos de los diferentes linajes, de las relaciones sociales de producción y reproducción y de la movilidad logística. Seguramente, estas concentraciones de sitios son un palimpsesto de la evolución del poblamiento desde el Neolítico Antiguo al Neolítico Final, y como resultado de la segmentación del primer linaje colonizador del VI milenio (ca. 5400/5300 cal BC) en varias familias extensas y clanes. Las concentraciones de túmulos funerarios en varios focos del paisaje (necrópolis) también podrían ser representativas de la segmentación interna del territorio tribal durante el Neolítico Medio (ca. 4600-3800 cal BC) y Final (ca. 38003000 cal BC).

La concentración de túmulos del entorno de Atapuerca no es un caso aislado en la provincia de Burgos, sino que hay otros focos megalíticos distanciados entre los que destaca la comarca de La Lora por la monumentalidad y la variedad de las estructuras funerarias. No obstante, la falta de prospecciones sistemáticas en otras comarcas burgalesas nos impide conocer si en esos focos megalíticos también hubo una asociación espacial tan nítida con los espacios habitacionales. Para una comprensión general del megalitismo burgalés se remite a varios autores (Uríbarri, 1975; Delibes y Rojo, 1997, 2002; Moreno, 2004).

La estructura territorial del Neolítico es muy coherente con el proceso de neolitización desde el Alto Ebro, con una marcada tendencia NE-SW y con una alta densidad de sitios en el tramo medio-alto del valle del Vena, al este de la sierra de Atapuerca. La densidad media del territorio es de 0.2 sitios por $\mathrm{km}^{2}$, marcando un máximo de 1.2 sitios por $\mathrm{km}^{2}$ en la isopleta ráster de mayor densidad (Kernel Density): el sur de la sierra de Atapuerca y la desembocadura del río Cueva con el río Arlanzón. Esta concentración significativa de sitios representa un complejo polifuncional diacrónico de cuevas, poblados estables, campamentos estacionales, sitios complementarios, túmulos y talleres de sílex con gran diversidad de emplazamientos y biotopos: sierra, fondo de valle, terrazas y borde del páramo. Este complejo singular es de gran interés para la comprensión del paisaje social de los grupos neolíticos, con una asociación espacial entre las prácticas económicas agropecuarias y las prácticas sociales, simbólicas y funerarias.

El segundo complejo de mayor densidad (0.9 sitios por $\mathrm{km}^{2}$ ) se localiza, precisamente, en el fondo del valle del río Vena (entorno de los humedales y túmulos de Atapuerca), el cual, a su vez, está precedido por otros dos complejos de concentración significativa: uno en los límites de la cuenca del Ebro y otro sobre la plataforma del Páramo Norte que permite el acceso al valle medio del río Vena. Los tres últimos complejos son considerados como los focos primigenios de la coIonización neolítica procedente del Alto Ebro a través del corredor de la Bureba, y están interconectados con el complejo de mayor densidad por un reguero de sitios donde dominan los poblados de diferente entidad. Otros focos de menor densidad se localizan de forma más dispersa y con significativos vacíos de poblamiento entre sí, destacando el complejo del fondo del valle del río Arlanzón en la zona oeste del MDT, la principal ruta de penetración a la cuenca del Duero.

Respecto a la temprana neolitización del área de estudio, subrayar que la Cueva de El Mirador ha proporcionado en el nivel MIR23 una de las dataciones sobre muestra de vida corta (Triticum dicoccum) más antiguas de la Meseta Norte: Beta-208134: 6300 \pm 50 , 5460-5080 cal BC (Vergés et al., 2008). Es previsible, por tanto, que las dataciones futuras del nivel MIR24 sobre agriotipos y fenotipos domésticos sean similares a las del MIR23 o ligeramente más antiguas, al ser el primer nivel neolítico de mayor profundidad. También es muy significativa la datación neolítica más antigua del nivel N9 de Cueva Mayor (Beta-222340: 6270 \pm 40 BP; 5330-5080 cal BC) (Carretero et al., 2008; Ortega et al., 2008; Alday et al., 2015, 2017).

Las dataciones del Neolítico Antiguo de Cueva Mayor y la Cueva de El Mirador junto con las del valle de Ambrona (Soria), -La Lámpara (KIA-21347: 54705320 cal BC) y La Revilla (KIA-21358: 5470-5290 cal BC) (Rojo et al., 2008)-, las de Mendandia (Condado de Treviño, cerca del contexto alavés del Alto Ebro), -NIII sup. (GrN-19658: 6120-5970 cal BC; GrN-22742: 6040-5970 cal BC), NII (GrN-22741: 5560-5390 cal BC) y NI (GrN-22740: 5440-5280 cal BC) (Alday, 2006)-, las de Peña Larga (Álava), -NIV (Beta-242783: 5710-5560 cal BC) (Fernández-Eraso, 2011) y las de la Cueva de La Vaquera (Segovia), -GrA-9226: 5480-5320 cal BC (Estremera, 2003)-, han supuesto un revulsivo sobre el inicio del proceso de neolitización del Alto Ebro y el NE de la Meseta Norte.

En consecuencia, el proceso de neolitización desde el Levante peninsular hasta la sierra de Atapuerca y el valle de Ambrona ha sido relativamente rápido, -de cerca de 200 a 300 años aproximadamente-, según las dataciones más antiguas del este, sur y sureste peninsular sobre muestras de vida corta de agriotipos 
y/o fenotipos domésticos: p.e., Guixeres de Vilobí (OxA26068: $6655 \pm 45$ : $5640-5490$ cal BC), El Cavet (OxA26061: 6536 $\pm 36:$ 5610-5390 cal BC), Cova d'en Pardo (Beta-231880: 6660 \pm 40: 5650-5510 cal BC), Cova de les Cendres (Beta-239377: 6510 \pm 40 : 5550-5380 cal BC), Barranquet (Beta-221431: 6510 \pm 50 : 5610-5370 cal BC), Cova de l'Or (UCIAMS-66316: 6475 \pm 25 : 54905380 cal BC), Mas d'ls (Beta-162092 y Beta-166727: 6600 50: 5620-5480 cal BC), Cova de la Sarsa (OxA26076: 6506 \pm 32 : 5530-5380 cal BC), Abric de la Falguera (Beta-142289: 6510 $\pm 80:$ 5620-5320 cal BC), Cueva de Chaves (GrA-38022: 6580 \pm 35 : 5610-5480 cal BC) y Cueva de la Carigüela (Col-1565: 6749 \pm 39 : 5725-5580 cal BC) (e.g., Bernabeu et al., 2016; García-Puchol et al., 2018). Posteriormente, el Neolítico del Alto Ebro y del NE de la Meseta Norte se expandirá a otras regiones norteñas y del NW peninsular, estando la agricultura presente, por ejemplo, en la Cueva de El Mirón (Cantabria) en el $\mathrm{V}$ milenio cal BC según la datación de una muestra de Triticum diccocum (GX-30910: 5550 440: 4460-4340 cal BC) (Peña-Chocarro et al., 2005).

\section{CONCLUSIONES}

Con las excavaciones arqueológicas realizadas en el entorno de la sierra de Atapuerca, y con las prospecciones sistemáticas intensivas de cobertura total sobre un área de estudio de 314 km² $(10 \mathrm{~km}$ de radio de Cueva Mayor), se ha demostrado la importante ocupación del territorio durante el Neolítico, con una secuencia radiocarbónica continua desde el Neolítico Antiguo al Neolítico Final (VI-IV milenio cal BC). La clasificación funcional de los asentamientos con la estadística multivariante de datos tecno-tipológicos, el SIG, los MDTs, las técnicas de análisis espacial y los test geoestadísticos han proporcionado nueva información para la comprensión del poblamiento.

El territorio manifiesta una alta densidad de yacimientos neolíticos, con una distribución espacial muy concentrada y con una articulación funcional de cuevas y galerías (zonas habitacionales, zonas de estabulación del ganado, zonas funerarias, espacios simbólicos de arte rupestre y de extracción de sílex cretácico), estructuras megalíticas (túmulos funerarios y menhires), poblados estables y estacionales, talleres de sílex y otros sitios satélites complementarios con actividades económicas recurrentes, temporales y efímeras: zonas de caza y recolección, zonas de producción agrícola, zonas de estabulación ganadera y altos de la movilidad pecuaria trasterminante.

Las fases del Epipaleolítico Microlaminar, el Mesolítico de Muescas y Denticulados y el Mesolítico Geométrico están ausentes en los sitios del entorno de la sierra de Atapuerca y en los niveles arqueoestratigráficos de la Cueva de El Mirador. De todo ello se deduce que hubo un proceso de colonización neolítica del territorio desde otros territorios adyacentes en el último tercio del VI milenio cal $\mathrm{BC}$, considerando que hay un hiato de unos 1500 años entre las dataciones del supuesto nivel mesolítico de Cueva Mayor, -por el momento sin restos de cultura material-, y los niveles del Neolítico Antiguo de Cueva Mayor y de la Cueva de El Mirador. El registro analizado en $314 \mathrm{~km}^{2}$, indica, por tanto, que en este territorio no hubo relaciones entre los últimos grupos de cazadores-recolectores y los primeros grupos agropecuarios.

Las dataciones radiocarbónicas de Cueva Mayor y Cueva de El Mirador (muestras de vida corta) son de las más antiguas de la Meseta Norte (ca. 5400/5300 cal BC). Según criterios tecnoculturales, radiocarbónicos, geoestratégicos y geoespaciales la neolitización del territorio procede del Alto Ebro, siendo el valle del Vena ,una de las zonas con mayor densidad de sitios-, el foco primigenio de la expansión a la sierra de Atapuerca y el valle del Arlanzón. La distribución espacial demuestra que hay un reguero continuo de sitios neolíticos en el límite de las cuencas del Ebro y el Duero, estableciéndose la conexión entre el valle del Vena (subcuenca del Arlanzón y cuenca del Duero) y el valle del Cerratón (subcuenca del Oca y cuenca del Ebro). En la neolitización progresiva del oriente de la Meseta Norte habría dos rutas de avance independientes prácticamente sincrónicas en el último tercio del VI milenio cal BC. La penetración desde el valle de Ambrona (Soria) por el corredor del Alto Duero se podría relacionar con la neolitización del territorio segoviano de la Cueva de La Vaquera. Por el contrario, la neolitización de la sierra de Atapuerca y la cuenca del Arlanzón es el resultado de la penetración desde el Alto Ebro a través del corredor de la Bureba.

La densidad de sitios neolíticos, la articulación funcional y la asociación espacial de poblados, cuevas, túmulos funerarios, talleres de sílex y otros sitios satélites complementarios, las galerías intrakársticas sacralizadas con actividad funeraria y simbólica, la correlación estadística espacial de las zonas de mayor explotación económica con las de mayor densidad habitacional, los diferentes complejos de densidad de sitios con varias concentraciones estadísticamente significativas, los focos primigenios de la neolitización, la forma de la densidad territorial, el patrón distribucional concentrado a macroescala y multiescalar, los significativos vacíos de poblamiento periféricos de la distribución, los registros arqueológicos y el resto de técnicas espaciales y geoestadísticas del SIG sugieren que el entorno de la sierra de Atapuerca es el centro de un territorio clánico o tribal con gran implantación temporal (VI-IV milenio cal BC).

Este territorio no es, por tanto, un simple corredor para atravesar del Alto Ebro a la cuenca del Duero en el VI milenio cal BC, sino que los primeros grupos neolíticos ya fueron conscientes de su gran potencialidad económica: alta productividad agrícola sobre suelos y terrazas cuaternarias, pastos fértiles pluriestacionales por el gradiente topográfico y la alta densidad hídrica (ríos, arroyos, fuentes, humedales y charcas estacionales), variedad de biotopos y ecotonos con múltiples recursos bióticos y abióticos minimizando los costes de 
distancia, alta diversidad geomorfológica, geológica, edáfica y paleoecológica. La localización, densidad, accesibilidad y calidad de los afloramientos de sílex neógenos y cretácicos es un factor secundario, pero también contribuyó para dotar al territorio de un mayor valor socioeconómico, tal como indica la ubicación de varios túmulos megalíticos sobre afloramientos de sílex.

La distribución territorial del Neolítico registrada es el resultado de un palimpsesto diacrónico de dos procesos socioeconómicos de gran amplitud temporal (VI-IV milenio cal BC). Primero, con la movilidad logística y residencial se produce la alineación, concentración y articulación funcional de poblados, cuevas, talleres de sílex y otros sitios satélites complementarios del proceso colonizador del Neolítico Antiguo, con un territorio tribal con vacíos de poblamiento periféricos. Segundo, los diferentes linajes generan en el Neolítico Medio y Final una segmentación interna del territorio tribal en varios complejos de sitios con alta potencialidad agropecuaria, con concentraciones de asentamientos polifuncionales y túmulos funerarios megalíticos, algunos asociados a humedales y sobre afloramientos de sílex. El proceso de neolitización del territorio es uno de los más antiguos de la Meseta Norte (ca. 5400/5300 cal $\mathrm{BC}$ ), quedando refutados los viejos argumentos historiográficos que hablaban de cultura de cuevas, vacíos poblacionales y de zonas retardatarias y marginales.

Otra conclusión del trabajo es que nos permite comprender, a través de la movilidad logística, la diversidad de restos carpológicos de los niveles neolíticos de las cuevas de la sierra de Atapuerca, cuyos géneros se relacionan con los pastos, praderas y tierras agrícolas de los poblados registrados en los valles: trigo común (Triticum aestivum/durum), escanda menor (Triticum dicoccum), y en menor cuantía, cebada (Hordeum vulgare), leguminosas (Pisum sativum), otros cultivos probables, plantas recolectadas y plantas sinantrópicas. La ganadería dominante está formada por ovicápridos (Ovis aries y Capra hircus), ya que los bóvidos (Bos taurus) y suidos (Sus domesticus) son más escasos. No obstante, la adscripción de los bóvidos y suidos como especies domésticas suele ser problemática, lo cual sugiere que la primera colonización del territorio (ca. 5400/5300 cal BC) se efectuó esencialmente con una ganadería de ovicápridos.

En definitiva, las primeras bases económicas de la producción neolítica territorial están sustentadas en la agricultura del trigo y en la explotación sistemática de los ovicápridos. Las evidencias empíricas de la cultura material, la distribución espacial, la articulación y la organización funcional avalan el concepto de «modo de vida agropecuario» para estas comunidades neolíticas, entendiendo por tal la integración de la agricultura y la ganadería a microescala y macroescala: con pequeñas granjas de explotación formadas por un espacio doméstico de materiales endebles (cabañas y silos de almacenaje), una zona de estabulación del ganado, una orla de tierras agrícolas, y con rutas de movilidad pecuaria trasterminantes de corta distancia por varios biotopos y ecotonos que articulan una densa red de cuevas, poblados, campamentos estacionales, túmulos funerarios, talleres de sílex y otros sitios con actividades económicas complementarias.

\section{AGRADECIMIENTOS}

La tesis doctoral inédita del autor (2014), base del artículo, fue financiada parcialmente por la Fundación del Patrimonio Histórico de Castilla y León (2006-2009). Los trabajos de campo del proyecto de investigación del autor («Prospecciones sistemáticas intensivas del entorno de la sierra de Atapuerca: El Holoceno») fueron financiados desde 1999 al 2007, o apoyados en la logística, por los proyectos «El Pleistoceno y Holoceno de la sierra de Atapuerca» (PB96-1026-C03-02; BXX20001258-C03-01; BOS2003-08938-C03-02; CGL200613532-C03-03), la UBU y la Fundación de Atapuerca. En el desarrollo de esta investigación (1999-2014), agradecemos a los doctores y licenciados que participaron desde 1999 al 2007 en las 10 campañas de prospecciones sistemáticas.

\section{BIBLIOGRAFÍA}

Alday, A., 2006. El legado arqueológico de Mendandia. Los modos de vida de los últimos cazadores en la Prehistoria de Treviño. Arqueología en Castilla y León, 15. JCyL, Valladolid.

Alday, A., Moral, S., Carvalho, A.F., Cerrillo, E., González, A., Juez, L., Ortega, A.I., 2009. Reflejos del Neolítico Ibérico. La cerámica boquique: caracteres, cronología y contexto. EDAR, Arqueología y Patrimonio, Barcelona.

Alday, A., Pérez, A., Carretero, J.M., Galindo, M.A., Adán, G., Arsuaga, J.L., 2015. Proofs of long-distance relations between Central Europe and Inland Iberian Peninsula during Neolithic and Bronze Age. Evidences from the material culture of the site of El Portalón (Sierra de Atapuerca, Burgos, Spain). Advances in Anthropology 5, 294-309.

Alday, A., Pérez, A., Iriarte, E., Francés, M., Arsuaga, J.L., Carretero, J.M., 2017. Pottery with ramiform-anthropomorphic decoration from El Portalón de Cueva Mayor site (Sierra de Atapuerca, Burgos) and the globalized symbolic world of the first Neolithic. Quaternary International (i.p.), doi.org/10.1016/j. quaint.2017.10.044.

Alonso, C., 2015. La tumba colectiva de El Hundido (Monasterio de Rodilla, Burgos) y su ritual funerario durante el Neolítico Final y el Calcolítico. Trabajos de Prehistoria 72 (1), 84-104.

Alonso, C., Jiménez, J., 2014. Contribución al estudio del poblamiento, modos de vida y ritual funerario del Neolítico Antiguo: El asentamiento al aire libre de El Prado (Pancorbo, Burgos). Zephyrus 74 (2), 41-64.

Alonso, C., Jiménez, J., 2015. El Neolítico en el corredor Alto Ebro-Alto Duero: dos hallazgos funerarios del Neolítico Antiguo y Reciente en Monasterio de Rodilla (Burgos). In: Gonçalves, V.S., Diniz, M., Sousa, A.C. (Coors.), Actas del V Congreso do Neolítico Peninsular (Lisboa, 2011), 540-546, Uniarq Waps. Universidade de Lisboa, Lisboa.

Allen, K., Green, S., Zubrow, E., (Eds.). 1990. Interpreting Space: GIS and Archaeology. Taylor \& Francis, London. 
Apellániz, J.M., Domingo, S., 1987. II. Los Materiales de Superficie del Santuario de la Galería del Sílex. Estudios sobre Atapuerca (Burgos). Universidad de Deusto y Diputación Provincial de Burgos, Bilbao.

Apellániz, J.M., Uríbarri, J.L., 1976. I. El santuario de la Galería del Sílex. Estudios sobre Atapuerca (Burgos). Universidad de Deusto y Diputación Provincial de Burgos, Bilbao.

Bernabeu, J., García, O., Barton, M., McClure, S., Pardo, S., 2016. Radiocarbon dates, climatic events, and social dynamics during the Early Neolithic in Mediterranean Iberia. Quaternary International 403, 201-210.

Bintliff, J.L., 2000. The concepts of «Site» and "Offsite Archaeology». In: Pasquinucci, M., Trement, F. (Eds.), Non-destructive Techniques Applied to Landscape Archaeology, 200215. Oxbow Books, Oxford.

Carbonell, E., Rodríguez, X.P., 2002. El Sistema Lògic Analític: origen, desenvolupament i perspectives de futur. Cota Zero 17, 106-116.

Carmona, E., 2014. Dataciones radiocarbónicas de contextos calcolíticos al aire libre en la cuenca media del Arlanzón (Burgos, España). SPAL 23, 27-48.

Carretero, J.M., Ortega, A.I., Juez, L., Pérez-González, A., Arsuaga, J.L., Pérez, R., Ortega, M.C., 2008. A Late Pleistocene-Early Holocene archaeological sequence of Portalón de Cueva Mayor (Sierra de Atapuerca, Burgos, Spain). Munibe $59,67-80$.

Conolly, J., Lake, M., 2009. Sistemas de Información Geográfica aplicados a la Arqueología. Bellaterra, Barcelona.

Chapman, H., 2006. Landscape Archaeology and GIS. Tempus, Stroud.

David, B., Thomas, J. (Eds.). 2008. Handbook of Landscape Archaeology. Left Coast Press, Walnut Creek.

Delibes, G., Rojo, M., 1997. C14 y secuencia megalítica en la Lora burgalesa: acotaciones a la problemática de las dataciones absolutas referentes a yacimientos dolménicos. In: Rodríguez, A. (Eds.), O Neolítico atlántico e as orixes do megalitismo. Actas do Coloquio Internacional (Santiago de Compostela, 1996), 391-414. Universidad de Santiago de Compostela.

Delibes, G., Rojo, M., 2002. Reflexiones sobre el trasfondo cultural del polimorfismo megalítico en la Lora burgalesa. Archivo Español de Arqueología 75, 21-35.

Diggle, P.J., 2003. Statistical Analysis of Spatial Point Patterns. Academic Press, London.

Estremera, M.S., 2003. Primeros agricultores y ganaderos en la Meseta Norte. El Neolítico de la Cueva de la Vaquera (Torreiglesias, Segovia). Arqueología en Castilla y León 11. Junta de Castilla y León, Zamora.

Expósito I., Burjachs F., Vergés J.M., 2017. Human trace on the landscape during the Holocene at El Mirador Cave (Sierra de Atapuerca, Spain): The palynological evidence. The Holocene 27 (8), 1201-1213.

Fernández-Eraso, J., 2011. Las cerámicas neolíticas de La Rioja Alavesa en su contexto: los casos de Peña Larga y Los Husos I y II. In: Bernabeu, J., M., Rojo, Molina, L. (Eds.), Las primeras producciones cerámicas. El VI milenio cal AC en la Península Ibérica, 117-129. Saguntum Extra 12, Universitat de Valencia.

Fish, S.K., Kowalewski, S.A., 1990. The Archaeology or Regions: A case for full-coverage survey. Smithsonian Series in
Archaeological Inquiry 3. Smithsonian Institution Press, Washington, D.C.

Gallant, T.W., 1986. Background noise and site definition: A contribution to survey methodology. Journal of Field Archaeology 13 (4), 403-418

García, M., Martín, J., Ortega, A.I., Martín, M.A., 2004. Grafismo rupestre postpaleolítico en la sierra de Atapuerca (Burgos): Salón del Coro, Galería del Silo, Galería Baja, Galería de las Estatuas y Cueva del Silo. Espacio, Tiempo y Forma, Prehistoria y Arqueología 14, 227-259.

García-Puchol, O., Bernabeu, J., Barton, M., Pardo, S., McClure, S., Díez, A., 2018. A bayesian aproach for timing the neolithization in mediterranean Iberia. Radiocarbon 60, 181-205.

Getis, A., Ord, J.K., 1996. Local Spatial Statistics: An Overview. In: Longley, P., Batty, M. (Eds.), Spatial Analysis: Modeling in a GIS Environment, 261-267. John Wiley \& Sons, New York.

Hair, J., Anderson, R., Tatham, R., Black, W., 1999. Análisis Multivariante. Prentice Hall Iberia, Madrid.

Hodder, I., Orton, C., 1990. Análisis Espacial en Arqueología. Crítica, Barcelona.

Lock, G., Stancic, Z., (Eds.). 1995. Archaeology and Geographical Information Systems. A European perspective. Taylor \& Francis, London.

Mallo, F., 1985. Análisis de Componentes Principales y técnicas factoriales relacionadas. Servicio de Publicaciones de la Universidad de León, León.

Marcos, F.J., 2006. La sierra de Atapuerca y el valle del Arlanzón. Patrones de asentamiento prehistóricos. Dossoles, Burgos.

Marcos, F.J., 2014. El entorno de la sierra de Atapuerca en el Neolítico, Calcolítico y Edad del Bronce: Tecnología lítica, Sistemas de Información Geográfica (SIG) y patrones de asentamiento. Tesis doctoral inédita. Universidad de Burgos.

Marcos, F.J., Díez, J.C., 2008. Propuesta y síntesis metodológica de Arqueología del Paisaje. Un diseño para la Prehistoria Reciente de la Meseta Norte. Zephyrus 61, 131-154

Martín, P., Rosell, J., Vergés, J.M., 2009. La gestión de los recursos faunísticos durante el Neolítico en la sierra de Atapuerca (Burgos): los niveles 19 y 20 de la Cueva del Mirador. Trabajos de Prehistoria 66 (2), 77-92.

Martínez, M.E., 1989. El yacimiento neolítico y la Edad del Bronce de Los Cascajos-El Blanquillo, Quintanadueñas, Burgos. Memoria de Licenciatura. Universidad de Valladolid.

Martínez, V., Aranburu, A., Yusta, I., Stoll, H., Arsuaga, J.L., 2010. Clima y ocupaciones en la Galería de Estatuas (Atapuerca, Burgos) en los últimos 14.000 años: Relatos de una estalagmita. Munibe 61, 89-102.

Merino, J.M., 1994. Tipología Lítica. Munibe, Suplemento 9. Sociedad de Ciencias Aranzadi, San Sebastián.

Mitchell, A., 2012. The ESRI Guide to GIS Analysis. ESRI Press, New York

Moreno, M.A., 2004. Megalitismo y Geografía: Análisis de los factores de localización espacial de los dólmenes de la provincia de Burgos. Studia Archaeologica, n 93. Universidad de Valladolid.

Navazo, M., 2006. Sociedades cazadoras-recolectoras en la sierra de Atapuerca durante el Paleolítico Medio: patrones de asentamiento y estrategias de movilidad. Tesis doctoral. Universidad de Burgos. 
Ortega, A.I., 2009. La evolución geomorfológica del karst de la sierra de Atapuerca (Burgos) y su relación con los yacimientos pleistocenos que contiene. Tesis doctoral. Universidad de Burgos.

Ortega, A.I., Martín, M.A., 2003. Las cavidades de Castrillo del Val. Cubía 6, 14-20

Ortega, A.I., Juez, L., Carretero, J.M., Ortega, M.C., Arsuaga, J.L., Pérez-González, A., 2008. El Neolítico en la nueva secuencia estratigráfica del yacimiento del Portalón de Cueva Mayor (sierra de Atapuerca, Burgos). In: Hernández, M.S., Soler, J.A., López, J.A. (Eds.), Actas del IV Congreso del Neolítico Peninsular (Alicante, 2006), 221-229. MARQ, Alicante.

Palomino, A.L., Delibes, G., Rojo, M.A., Abarquero, F.J., Moreno, M., Negredo, M.J., 2006. El Turrumbero de la Cañada. Arquitectura megalítica al pie de la sierra de Atapuerca (Burgos). In: Bicho, N., Carvalho, A.F. (Eds.), Actas del IV Congreso de Arqueología Peninsular (Faro, 2004), Vol. 5, 143-155. Universidade do Algarbe, Faro.

Peña-Chocarro, L., Zapata, L., Iriarte, M.J., González, M., Guy, L., 2005. The oldest agriculture in northern Atlantic Spain: new evidence from El Mirón Cave (Ramales de la Victoria, Cantabria). Journal of Archaeological Science 32 (4), 579-587.

Renfrew, C., Bahn, P., 1993. Arqueología, Teoría, Métodos y Práctica. Akal, Madrid.

Ripley, B.D., 1981. Spatial Statistics. John Wiley, Chichester.

Rodríguez, A., Allué, E., Buxó, R., 2016. Agriculture and livestock economy among prehistoric herders based on plant macro-remains from El Mirador (Atapuerca, Burgos). Quaternary International 414, 272-284.

Rojo, M.A., Kunst, M., Garrido, R., García, I., Morán, G., 2008. Paisajes de la Memoria: Asentamientos del Neolítico Antiguo en el valle de Ambrona (Soria, España). IAA-UVa. Serie Arte y Arqueología 23, Valladolid.
Rojo, M.A., Garrido, R., Tejedor, C., García, I., Alt, K.W., 2015. El tiempo y los ritos de los antepasados: La Mina y el Alto del Reinoso, novedades sobre el Megalitismo en la cuenca del Duero. ARPI 3, 133-147.

Rojo, M.A., García, I., Garrido, R., Tejedor, C., Subirá, E., García, J., Sesma, J., Gibaja, J.F., Unzu, M., Palomino, A.L., Jiménez, I., Arroyo, E., Arcusa, H., 2016. Enterramientos del Neolítico antiguo en el interior peninsular: nuevos datos para una actualización de la evidencia empírica. In: Del Neolític a l'Edat del Bronze en el Mediterrani occidental. Estudis en homenatge a Bernat Martí Oliver, 181-210. TV SIP 119. Diputación de Valencia, Valencia.

Uríbarri, J.L., 1975. El fenómeno megalítico en la Provincia de Burgos. Institución Fernán González, Burgos.

Uríbarri, J.L., Martínez, J.M., 1987. Primeros asentamientos humanos en el término municipal de la ciudad de Burgos. Caesaraugusta $64,135-156$.

Uríbarri, J.L., Martínez, J.M., Leis, I., 1987. Primeros asentamientos humanos en la ciudad de Burgos. I. El yacimiento arqueológico del Castillo y Cerro de San Miguel. Aldecoa, Burgos.

Vergés, J.M., Allué, E., Fontanals, M., Morales, J.I., Martín, P., Carrancho, A., Expósito, I., Guardiola, M., Lozano, M., Marsal, R., Oms, X., Euba, I., Rodríguez, A., 2016. El Mirador cave (Sierra de Atapuerca, Burgos, Spain): A whole perspective. Quaternary International 414, 236-243.

Wheatley, D., Gillings, M., 2002. Spatial Technology and Archaeology. The Archaeological Application of GIS. Taylor \& Francis, London. 